\title{
Antibacterial properties and toxicity from metallic nanomaterials
}

\author{
This article was published in the following Dove Press journal: \\ International Journal of Nanomedicine \\ 24 May 2017 \\ Number of times this article has been viewed
}

\author{
Gina V Vimbela ${ }^{1, *}$ \\ Sang M Ngo ${ }^{2, *}$ \\ Carolyn Fraze $^{3}$ \\ Lei Yang ${ }^{4,5}$ \\ David A Stout ${ }^{5-7}$
}

'Department of Chemical Engineering, ${ }^{2}$ Department of Electrical Engineering, California State University, Long Beach, CA, ${ }^{3}$ Brigham Young University Idaho, Rexburg, ID, USA; ${ }^{4}$ Department of Orthopaedics, Orthopaedic Institute, The First Affiliated Hospital, International Research Center for Translational Orthopaedics (IRCTO), Soochow University, Suzhou, Jiangsu, People's Republic of China; ${ }^{6}$ Department of Mechanical and Aerospace Engineering, ${ }^{7}$ Department of Biomedical Engineering, California State University, Long Beach, CA, USA

*These authors contributed equally to this work
Correspondence: David A Stout Department of Mechanical and Aerospace Engineering, I 250 Bellflower Blvd, ECS-632 Long Beach, CA 90840, USA

Tel +I 562985 I502

Email david.stout@csulb.edu

Lei Yang

Orthopaedic Institute of Soochow University, 3 I 3 Buidling \#I, 708 Renmin Road, Suzhou, Jiangsu 215006, People's

Republic of China

Tel +865I26778 I540

Email leiy@suda.edu.cn

\begin{abstract}
The era of antibiotic resistance is a cause of increasing concern as bacteria continue to develop adaptive countermeasures against current antibiotics at an alarming rate. In recent years, studies have reported nanoparticles as a promising alternative to antibacterial reagents because of their exhibited antibacterial activity in several biomedical applications, including drug and gene delivery, tissue engineering, and imaging. Moreover, nanomaterial research has led to reports of a possible relationship between the morphological characteristics of a nanomaterial and the magnitude of its delivered toxicity. However, conventional synthesis of nanoparticles requires harsh chemicals and costly energy consumption. Additionally, the exact relationship between toxicity and morphology of nanomaterials has not been well established. Here, we review the recent advancements in synthesis techniques for silver, gold, copper, titanium, zinc oxide, and magnesium oxide nanomaterials and composites, with a focus on the toxicity exhibited by nanomaterials of multidimensions. This article highlights the benefits of selecting each material or metal-based composite for certain applications while also addressing possible setbacks and the toxic effects of the nanomaterials on the environment.
\end{abstract}

Keywords: antibacterial reagents, nanomaterials, synthesis, metals, nanostructure, nanoscale, antibiotic resistance, toxicity, drug delivery

\section{Introduction}

Bacteria are serious and potentially life-threatening agents, capable of promoting infectious diseases. The bubonic/pneumonic plague ${ }^{1}$ pandemic of the 14th century and the transmission of virulent cholera ${ }^{2}$ are both examples of bacteria acting as causative agents for infection. The bubonic/pneumonic plague, or the Black Death, was one of the most devastating disease outbreaks in human history, killing $~ 50$ million people worldwide. ${ }^{3}$ Although the etiology of the disease remained highly controversial until recently, the gram-negative Yersinia pestis was confirmed to cause the Black Death and later epidemics over the course of four centuries. ${ }^{4}$ Pandemics of cholera, a disease caused by Vibrio cholerae, have affected millions of people since the early 1800s. The second cholera ${ }^{5}$ pandemic (1832) alone claimed the lives of over 15,000 people throughout Asia and Europe. The magnitude and severity of such outbreaks left local governments ill-equipped to supply necessary aid, eventually leading to the establishment of the World Health Organization (WHO) in 1945. The WHO worked to provide local governments with vaccines, laboratory personnel training, and equipment ${ }^{2}$ to mitigate the effects of outbreaks. Despite programs from the WHO set in place, outbreaks of diseases such as typhoid and scarlet fever led to drastic fluctuations in morbidity and mortality rates ${ }^{3}$ in the 20th century. The discovery of the role of bacteria as infectious agents propelled the scientific community toward the development of synthetic antibacterial agents. 
Introduced in 1910, salvarsan was the first antimicrobial agent to be synthesized as a remedy to syphilis. The era of antibiotics soon followed, and antimicrobial agents such as chloramphenicol, nalidixic acid, and macrolides were introduced into clinics.

The introduction of antibiotics in the 20th century provided temporary relief to infectious bacterial pathogens. The emergence of antibiotic-resistant bacteria has been traced to several dynamic mechanisms of action consistent with bacterial roles against antimicrobial host defense. ${ }^{6}$ Moreover, bacterial pathogens have also significantly evolved effective countermeasures against antibacterial agents stemming from overexposure to antibiotics, such as efflux pumps that remove the antibacterial agent before it can reach its target site and exert its effect. ${ }^{7}$

Methods for overcoming the emergence of these resistant strains have delved into the development of new antibiotic drugs boasting chemical diversity, such as the antibiotic daptomycin found in soil actinomycetes. ${ }^{8}$ Additionally, identification of antibiotic-producing bacteria such as that found on the European beewolf ${ }^{9}$ (a hunting wasp) has proven the existence of additional antibiotics from natural, previously unexplored sources. Developments in these areas, however, have not produced sufficient advancement against the rapidly increasing number of resistant bacterial strains. ${ }^{10,11}$ Nontraditional antimicrobial agents have now been identified as promising tools against bacteria resistant to traditional antibiotic drugs. ${ }^{12}$

One type of nontraditional antimicrobials recently introduced is nanomaterials. Nanomaterials have proven to demonstrate toxic effects against several bacterial strains during in vitro studies. Because of these results, nanomaterials could be promising in several biomedical applications, including drug and gene delivery, tissue engineering, and imaging techniques. Additionally, these materials could be used as a vehicle for delivering a range of therapeutic agents, including drugs, pharmaceuticals, and antibodies. Paul Ehrlich first sparked the idea of developing drug delivery systems, pioneering the development of drug targeting nanoparticles, and introducing nanomaterials for possible use in the medical field. ${ }^{13}$

Since early 2005, nanomaterials have been widely studied for possible use in both medical and pharmaceutical applications. ${ }^{13}$ These materials are characterized by exhibiting at least one dimension measuring $100 \mathrm{~nm}$ or less and can be metallic, semiconducting, polymer, or carbon based. Reports of antibacterial activity in nanomaterials have stemmed from observed biophysical interactions occurring between nanoparticles and bacteria, including cellular uptake and nanoparticle aggregation, leading to membrane damage and toxicity. ${ }^{14}$ In particular, metallic nanomaterials (such as silver, gold, copper, and titanium) exhibit favorable physicochemical characteristics resulting in significant levels of antibacterial activity. This review focuses on the recent advancements made in metallic nanomaterials as antibacterial agents, with a focus on their toxicity and antibacterial activity based on the structure, dimension, and size of nanomaterials. Furthermore, the benefits of using nanomaterials of silver, gold, copper and titanium metals, as well as zinc and magnesium oxides, will be discussed.

\section{Silver nanomaterials}

Silver as an antibacterial reagent can be traced back thousands of years to early civilizations when it was utilized for food preservation and production of potable water. ${ }^{15}$ Silver was introduced into the medical field for uses in wound healing and burn treatment when its antibacterial properties were discovered. ${ }^{16}$ In the early 1940s, the era of antibiotics emerged, and silver was largely replaced by penicillin. ${ }^{17}$ Now as antibiotic-resistant bacterial strains continue to emerge and rise in number, silver has been reintroduced as a promising material in the development of new bactericides.

In recent years, several studies have established the ability of silver nanomaterials to exhibit unique electronic, optical, and chemical properties. ${ }^{18-23}$ Studies are exploring the possibility of a relationship between physicochemical characteristics of silver nanomaterials and their delivered magnitude of toxicity. Shapes such as beads, ${ }^{19}$ rods, ${ }^{20}$ mats,${ }^{21}$ sheets, ${ }^{22}$ and nanoprisms ${ }^{23}$ are being developed and investigated for their specific antibacterial effects. Recently, studies have reported that size and surface coating of silver nanoparticles (AgNPs) play a large role in antibacterial activity, with smaller nanoparticles observed to deliver a higher magnitude of toxicity. ${ }^{14,15,19}$ Furthermore, a study using gene deletion mutants to identify the physiological pathways involved in the antibacterial response of gram-negative bacteria Escherichia coli to AgNPs techniques reported from its findings that the mechanism, in addition to the magnitude, of delivered toxicity may be strongly influenced by the physicochemical properties of the nanoparticle. ${ }^{24}$

Many studies have sought to establish a mechanism of action of antibacterial activity exhibited by silver in both its colloidal and ionic form. Two leading theories on the proposed mechanism suggest 1) a disruption of membrane functionality from an interaction between released $\mathrm{Ag}^{+}$ions and the cell membrane and 2) extensive cell membrane 
damage caused by the formation of reactive oxygen species (ROS) ultimately causing damage to the cell due to oxidative stress (Figure 1). ${ }^{24-26}$ In brief, the first mechanism suggests that $\mathrm{Ag}^{+}$ions released from AgNPs can bind with thiol groups $(-\mathrm{SH})$ of proteins and enzymes found on the cellular surface, causing destabilization of the cellular membrane and a breakdown of the ATP synthesis pathway. AgNPs may then adhere to the membrane wall, causing holes through which they can later penetrate the bacteria and interact with intracellular components or proteins containing sulfur. The second mechanism suggests that ROS, such as singlet oxygen, can be produced at the cell membrane and lead to irreversible damage to DNA replication affecting metabolic processes and cell division. ${ }^{25}$ As a better understanding is gained on both mechanisms, several reports suggest the first as causing the most significant damage to bacteria. This section will examine advancements in the antibacterial properties of silver nanomaterials due to different structures and their toxicity activities.

\section{Nanoparticles}

Novel techniques for synthesis of silver nanomaterials are being studied to identify green alternatives to conventional synthesis and to explore the properties exhibited by composite and hybrid silver nanomaterials. ${ }^{27,28}$ Nanoparticles are categorized as particles that behave as a single unit with respect to transport and reactivity. AgNPs can be immobilized

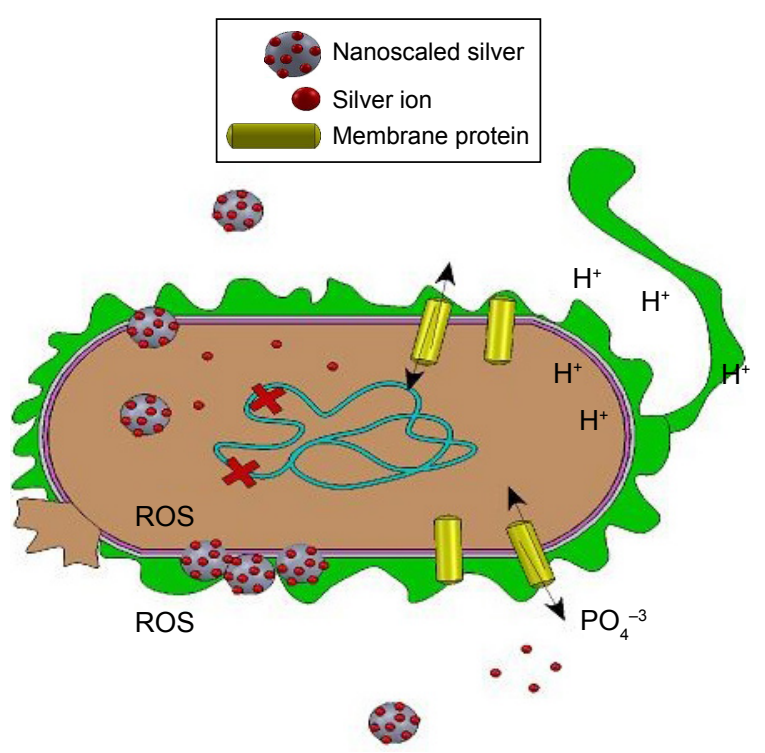

Figure I Formation of reactive oxygen species (ROS) and disruption to membrane functionality by nanosilver.

Notes: Antibacterial activities from silver are due to the formation of ROS and disruption of membrane functionality. Formation of ROS causes oxidative stress, which leads to cellular damage. The interaction between the released ions of nanosized silver results in disruption of the membrane functionality. and coated onto surfaces or may be blended with polymers to form composites for better use of their antimicrobial actions. ${ }^{29}$ The excellent bactericidal effects demonstrated by synthesis of such composites suggest high potential of nanoparticles in water treatment, medical devices, burn dressings, and food preservation. Most notably, recent advancements in the synthesis of composites and hybrids suggest potential in drug delivery systems in tissue engineering applications. For this reason, silver nanomaterials have been the source of substantial attention in the medical and technological fields.

Synthesis of AgNPs can be performed through chemical or physical techniques. Conventional synthesis of AgNPs requires an initial reduction of metal salts into pure metals and stabilizing or capping agents to prevent the aggregation of nanoparticles into clusters. They are most commonly synthesized via chemical reduction of silver nitrate or silver tetrachloride resulting in stable colloidal dispersions in solvent. ${ }^{30}$ Green alternatives to harsh reducing and stabilizing agents, as well as costly energy consumption, are being investigated and proposed as commercialization of AgNPs continues to rise. Such alternatives include biogenic methods, which use plant extracts, bacteria, fungi, and yeasts as solvents, reducing/capping agents, and/or stabilizing agents. ${ }^{31}$

Eco-friendly, simple synthesis methods utilizing plant and bark extracts are capable of producing polydispersed AgNPs with diameter ranges within $20 \mathrm{~nm}$ apart. ${ }^{32}$ Sankar et $\mathrm{al}^{33}$ used Origanum vulgare, or oregano, plant leaf extract to synthesize spherical AgNPs displaying cytotoxicity against human lung cancer A549 cell line during in vitro experiments. The study found a direct dose dependence between increased (AgNP) concentration to cytotoxicity against the cancer cell line, with a significant $85 \%$ of cell mortality, although anticancer activity mechanism is yet to be understood. Similarly, Nayak et $\mathrm{al}^{34}$ synthesized crystalline and spherical AgNPs using bark extracts of Ficus benghalensis and Azadirachta indica and observed antibacterial activity against gram-positive and -negative bacteria, in addition to cytotoxicity against osteosarcoma MG-63 cell line.

Use of cell-free culture supernatants of bacteria for AgNP synthesis is favorable due to its simplicity and ease of genetic modification, although the exact mechanism of this extracellular synthesis is not known. Studies have reported supernatants of Bacillus cereus, Bacillus subtilis, Bacillus licheniformis, E. coli, Enterobacter cloacae, Klebsiella pneumonia, Lactobacillus acidophilus, Staphylococcus aureus, and Pseudomonas aeruginosa to induce synthesis of AgNPs. ${ }^{35}$ Priyadarshini et al ${ }^{36}$ recently reported Bacillus flexus S-27 as a potential candidate for extracellular synthesis 
of AgNPs that exhibit antibacterial properties against clinically isolated multidrug-resistant bacterial pathogens. Although size of the AgNPs could not be controlled by synthesis factors, AgNPs were determined to be triangular and spherical shaped. Gahlawat et $\mathrm{al}^{37}$ characterized a novel bacterial strain as Ochrobactrum rhizosphaerae and synthesized spherical AgNPs as antimicrobial agents against cholera. The study was able to isolate the biomolecule present in the culture supernatant responsible for synthesis and capping of the AgNPs and identify it as a glycoprotein exopolymer. Observations of antibacterial characteristics demonstrated inhibition of bacterial growth and a reduction in the metabolic activity and cell viability against $V$. cholerae, suggesting a strong potential of the AgNPs for cholera treatment.

Yeast, a single-celled fungus, has recently been identified as a promising candidate for AgNPs synthesis due to its longterm use in industrial scale productions. Eugenio et $\mathrm{al}^{38}$ report the bioproduction of AgNPs and AgCl-NPs using seven yeast isolates from a termite gut. Two strains of Candida lusitaniae (named SNPP1 and SNPP2) of the seven proved to be particularly efficient, with SNPP1 displaying a more uniform size and shape distribution. Agglomerations of AgNPs and $\mathrm{AgCl}-\mathrm{NPs}$ were observed to be between the outer region of the plasma membrane and the inner cell wall of yeast. No interaction between synthesized AgNPs and AgCl-NPs and yeast intracellular organelles, therefore understanding of whether the synthesized NPs were transferred to their location from within the cell or were deposited there from the cell medium is unknown, requiring further research in the precise mechanism of nanoparticle synthesis.

Other green alternatives for the synthesis of AgNPs include photoinduced or photocatalytic reduction and onestep synthesis of AgNPs using carbon dots as reducing and stabilizing agents. Banasiuk et $\mathrm{al}^{39}$ reduced the synthesis time by using commercially available LED lights to significantly reduce energy consumption. Furthermore, Jin et al reported a novel green method of stabilizing and reducing AgNPs by fluorescent carbon dots. Previously, carbon dots have been reported to exhibit reducing and oxidizing properties, ${ }^{40}$ in addition to predicted stabilizing properties due to various $-\mathrm{COOH}$ and $-\mathrm{OH}$ groups existing on their surface. ${ }^{41}$ With this in mind, Jin et al investigated the synthesis of AgNPs by using carbon dots as reducing and stabilizing agents and the effects of doping the carbon dots in sulfur to modify the size and antibacterial properties of the resulting AgNPs. The group concluded that reduction method was highly dependent upon $\mathrm{pH}$ levels, with higher reducing activity correlating with higher $\mathrm{pH}$ values. Sulfur doping of the carbon dots fabricated much more stable AgNPs, which may be attributed to high binding energy of sulfur to silver.

The specific physicochemical properties of a nanomaterial play an intrinsic role in its functionality and use. AgNPs may be produced into metallic or composite structures of one or more nanoscale dimensions. Structures such as nanobeads, nanocrystals, and quantum dots are examples of nanostructures with the highest reported antibacterial properties. Because of their uniquely high volume to surface area ratio, they are particularly promising for therapeutic and drug delivery systems. For example, a study on the physiological reactions of $E$. coli to AgNPs of different surface charge and size was found to affect the antibacterial mechanism exhibited by AgNPs. ${ }^{24}$ While positively surface charged AgNPs exhibited equal effects to silver nitrate, only the smaller citrate-based NPs caused $E$. coli to initiate a response similar to its response to silver ion. In another study, AgNPs were synthesized during in situ formation of physically crosslinked chitosan (CS) hydrogel beads. ${ }^{42}$ The formed AgNPs smoothed the surface morphology of the $\mathrm{CH} / \mathrm{Ag}$ hydrogel beads, while also decreasing the amount of intact drug, which could be loaded onto the beads. Loading of ibuprofen into resulting nanoparticles showed prolonged release of drug with increased amount of AgNPs in the $\mathrm{CH} / \mathrm{Ag}$ beads, making the beads particularly favorable for controllable drug release applications.

\section{Nanorods and nanofibers}

Silver structures, such as nanorods, nanotubes, and nanofibers, are tubular nanostructures with applications in drug delivery, phototherapy, and water filtration. These nanostructures are versatile because of their potential in controlled release systems. For example, the fibrin morphology of composite $\mathrm{Ag} /$ silk fibroin nanofibers is capable of controlling $\mathrm{Ag}^{+}$ion release, allowing for increased local antibacterial activity at low silver concentrations. ${ }^{43}$ Moreover, due to their tubular structures, these nanostructures can be composed of layers in different materials, adding to their versatility and uniqueness. Black et $\mathrm{al}^{44}$ exploited the photothermal properties of gold and developed gold core-silver shell nanorods as bacterial antibodies. These were used to specifically target bacterial walls and as therapeutic treatment by plasmonic heating and light irradiation. The silver coating over the gold center intensified the heating effects when irradiated by light, with simultaneously increasing antibacterial activity against bacterial walls of both gram-positive and gram-negative bacteria. Similarly, Hassan et al studied bimetallic composites and their capability to improve single-metal properties 
by bimetallization. A bimetallic composite demonstrating a spider-net morphology was prepared using zinc oxide, silver, and polyurethane $(\mathrm{ZnO}: \mathrm{Ag} / \mathrm{PU}) .{ }^{45} \mathrm{PU}$ is a biocompatible thermoplastic polymer that has desirable mechanical properties and is water insoluble. Antibacterial activity of $\mathrm{ZnO}$ and $\mathrm{ZnO}$ :Ag was tested using E. coli. $\mathrm{ZnO} / \mathrm{PU}$ hybrid nanofibers demonstrated significant antibacterial activity, while $\mathrm{ZnO}$ :Agdoped PU showed complete inhibition of E. coli. Proliferation of NIH $3 \mathrm{~T} 3$ mouse fibroblast cells was analyzed in vitro to test bimetallic composite compatibility, results demonstrated noncytotoxic behavior between the cell line and composite. The synergism of the metallic properties in $\mathrm{ZnO}$ :Ag composite signals its high potential in water filtration uses.

\section{Nanomats}

Structures such as nanofilms, nanosheets, and nanomats are two-dimensional nanostructures with a thickness within the $1-100 \mathrm{~nm}$ range size. These structures are particularly useful as nanohybrids and composite materials with biocompatible polymers. For example, nanofiber mats embedded with chitosan-based silver nanoparticles (CS/AgNPs) were blended with polyvinyl alcohol (PVA) and the effects on E. coli were studied. ${ }^{21}$ In addition to the increased antibacterial efficacy demonstrated by the nanofiber systems, results suggest blending of CS-based systems with PVA produced electrospun fiber mats more easily and with higher mechanical ability making it possible to further explore utilization of promising and biocompatible CS/AgNP-embedded systems in antibacterial applications. Inspired by the adhesive thread found in Mytilus edulis foot protein 5 (Mefp-5) of mussels, synthesis of uniform AgNPs on functionalized polydopamine-graphene nanosheets (PDA-GNS) was studied. ${ }^{22}$ The authors suggested that utilization of a natural selfpolymerizing PDA on functionalized surfaces could provide effective methods for synthesis of highly uniform AgNPs on hybrid materials exhibiting strong biocidal properties with strong potential in clinical and environmental applications.

\section{Complex nanostructures}

Nanoprisms, matrices, and dendritic structures are complex nanostructures the potential of which is far from being fully exploited. For example, encapsulated anisotropic AgNPs were synthesized in biocompatible polymer pluronic F-127 into triangular nanoprisms. ${ }^{46}$ The resulting nanoprisms had an average edge length between 30 and $50 \mathrm{~nm}$ and thickness of 4 and $6 \mathrm{~nm}$. Pluronic F-127 is a synthetic triblock copolymer consisting of poly(ethylene oxide)-poly(propylene oxide)poly(ethylene oxide) chains that can self-assemble into micelles to form different close-packed surfaces. Pluronic can bind to the surface of the nanoparticles and form a protective layer by hydrophobic association of the PPO blocks. Surface modifications of synthesized AgNPs were developed to prevent aggregation in biological media, increase stability, and reduce toxicity and probable immune response from living organisms. Antibacterial activity exhibited by the triangular nanoprisms suggests a higher rate of $\mathrm{Ag}^{+}$ion release possibly from the crystalline tips and edges, therefore, being ultimately useful for therapeutic applications.

\section{Toxicity}

The impact that novel nanoparticles and nanostructures may have on biological organisms and the environment must be understood to minimize potentially detrimental effects of these nanoparticles in any application. Recent studies have investigated the cytotoxic effects of AgNPs on the human body, specifically on the respiratory and cardiovascular systems, osteoblasts and osteoclasts, DNA, and embryo development malformations. ${ }^{47}$ Many recent studies aim to counter the lack of consensus in earlier investigations, where large variability between AgNPs synthesis led to widely different conclusions on the toxicological effects of size-varying AgNPs.

Gliga et $\mathrm{al}^{48}$ investigated physicochemical effects by studying the release of silver ions by AgNPs of 10, 40, 50, and $75 \mathrm{~nm}$ and capping agents against healthy human lung cells. Although the capping agent was not found responsible for mediating toxic effects, release of $\mathrm{Ag}^{+}$into the cell medium was found to be directly proportional to the total surface of the particle and thus size. Furthermore, investigation of the cellular uptake of $\mathrm{Ag}^{+}$showed a higher total cellular content that did not correlate with the most toxic NP size. The authors suggest that the higher $\mathrm{Ag}^{+}$content within the cell must be a result of intracellular transformation of AgNPs to $\mathrm{Ag}^{+}$. The composition of experimental media also plays a role in the release of silver. For information on the differences of toxic effects dependent on media composition, the following reviews on the subject are recommended. ${ }^{49-52}$

Damage to specific cells and cellular structures is also actively studied to determine specific biological responses and possible toxicological mechanisms between AgNPs and the structures. Incurred DNA damage by $\mathrm{Ag}^{+}$release is noted to be size independent. One study reported that DNA damage (Figure 2) occurred in all tested samples (regardless of NP size) after a 4-hour incubation period. ${ }^{48}$ Although the exact mechanism for this could not be determined, authors suggest that DNA damage could occur due to AgNP interaction with 


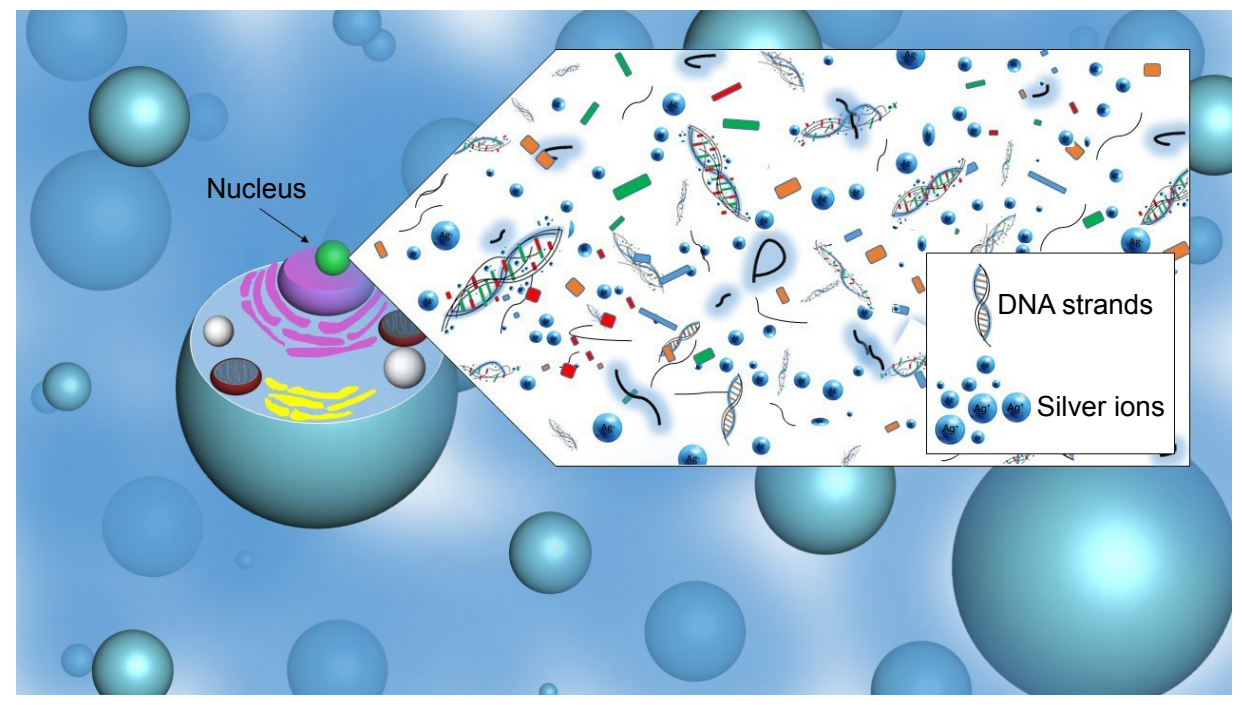

Figure 2 Damaged DNA strands due to silver ions in cell nucleus.

Note: Nanosized silver releases silver ions, which interacts with DNA strands within the cellular nucleus, which results in DNA damage.

DNA repair pathways as previously reported for AgNPs. Damage to mitochondria leading to stimulation of apoptotic pathways has also been observed as a result of AgNP exposure. The study determined cytotoxicity of AgNPs to be mediated by free radical-independent mechanisms since free radicals were determined to play no major role in cytotoxic behavior. ${ }^{53}$ Cytotoxicity of AgNPs on red blood cells (RBCs) is of particular interest, as the introduction of AgNPs into the body suggests a high probability of these into the blood. Chen et al ${ }^{54}$ found cytotoxicity effects of 15 , 50, and $100 \mathrm{~nm}$ AgNPs on RBC to be higher when they are a smaller size, while biological-based nanoparticles with larger sizes exhibit higher cytotoxic effects. This points to a possible difference in toxicity mechanism from one type of nanoparticle to the next. The mechanism alludes to higher reactivity between positively charged silver particles and negative surface charge of RBCs, thus more interaction. The study also established an optimal size, $\sim 50 \mathrm{~nm}$, for interaction into the cytoplasm of RBC. Further studies are needed to determine the exact mechanism that gives rises to the selectivity of size and to determine the differences in biological-based nanoparticles vs AgNPs. Furthermore, the possibility of the biocompatibility of orthopedic implants being compromised by the cytotoxicity of AgNPs against osteoblasts and osteoclasts is a major concern. In a study conducted by Pauksch et al, ${ }^{55}$ osteoblasts were found to have a higher susceptibility to toxicological effects of less than $5 \mathrm{~nm}$ sized AgNPs than osteoclasts. In this study, AgNPs at $\sim 30 \mathrm{~nm}$ size released more $\mathrm{Ag}^{+}$then the larger AgNPs, alluding to a similar size selectivity as that of the $\mathrm{RBC}$ and
AgNP interaction. Antibacterial activities due to AgNPs against bacteria cells are promising from their observation of toxicities in previous studies.

Studies on the environmental toxicity of AgNPs suggest that the impact of nanosilver may be dependent on the different organisms that come into contact with the materials. ${ }^{56}$ In one study, 0.1 to $1,000 \mu \mathrm{M} \mathrm{AgNPs} \mathrm{in} \mathrm{aqueous}$ media were introduced to aquatic organisms and were found to show different accumulation abilities in each organism. Another study suggests that the toxicity of AgNPs on aquatic organisms of different trophic levels might be alleviated by humic substances. ${ }^{57}$ The authors suggest that this alteration of toxicity by the humic substance may be through a possible electrostatic barrier limiting the interaction between AgNPs and the aquatic organisms.

Decreasing the size of a nanomaterial leads to a significant increase in surface area relative to volume. Several articles have reported cellular uptake, endocytosis, and the efficiency of particle processing in the endocytic pathway to be dependent on particle size. ${ }^{58}$ However, recent studies report agglomeration of AgNPs to occur quickly in proteinstabilized dispersions for particles of sizes between 20 and $50 \mathrm{~nm} .{ }^{59}$ The formation of agglomerations is reported to decrease hemolytic cytotoxicity by decreasing the effective surface area to volume ratio and, ultimately, the release of $\mathrm{Ag}^{+}$and the generation of ROS. ${ }^{60}$

\section{Summary}

Advances in synthesis techniques of silver nanomaterials have increased the number of applications, in which silver 
nanomaterials may be used as antibacterial reagents. Novel synthesis techniques for silver nanostructures have explored biogenic methods that include plant extracts, bacteria, fungi, and yeasts as solvents, reducing/capping agents, and/or stabilizing agents, providing green alternatives to conventional synthesis. Moreover, novel green synthesis methods for AgNPs production also included photoinduced or photocatalytic reduction and one-step synthesis of AgNPs using carbon dots as reducing and stabilizing agents, reducing synthesis time and high energy consumption compared to classical synthesis methods. Additionally, silver nanomaterials of varying size and structure exhibited varying antibacterial properties. For example, synthesized triangular nanoprisms released higher amounts of silver ions than nanoparticles of the same size and thus demonstrated a higher antibacterial activity. However, nanoparticles of smaller size but same morphological characteristics showed higher antibacterial activity due in large part to ionization rates of the silver ion being higher and also because of the higher chance of the nanoparticle entering into the bacterial cell wall at a smaller size. The potential of nanosized silver as an antibacterial reagent is irrefutable.

\section{Gold nanomaterials}

Utilization of colloidal gold as a coloring agent for glass tinting and ceramic adornment can be dated back to as early as the fifth century. ${ }^{61}$ Michael Faraday's Bakerian Lecture on the "Experimental Relations of Gold (and other Metals) to Light" in 1857 later reintroduced gold in its nanoparticle dimensions to the scientific community. ${ }^{62,63}$ This lecture catalyzed research into the physicochemical properties exhibited by gold nanoparticles (AuNPs) and launched these into tremendous attention for uses in water treatment, catalysis, biosensing, and optics, as well as for therapeutic applications. ${ }^{62,64}$ Further research has shown AuNPs as promising bactericidal agents due to their versatile optical and photothermal properties. ${ }^{65}$ Advancements in the synthesis and applications of AuNPs as antibacterial reagents are imperative in the fight against antibacterial resistance. ${ }^{8,66-69}$ Although not as well studied as the antibacterial mechanism of AgNPs, antibacterial activities of AuNPs are believed to proceed mainly in the two following ways: 1) a change in the membrane potential and prevention of ATPase activities lead to a decline in cellular metabolism (Figure 3A) and 2) the subunit of the ribosome for tRNA binding is inhibited leading to a collapse in biological processes (Figure 3B). ${ }^{69}$ In the following sections, advances in the development of gold nanostructures are discussed, including novel synthesis techniques and fabrication of promising nanocomposites. The contribution to their exhibited antibacterial activities stemming from unique morphological features is also discussed.

\section{Nanoparticles}

The rapid advancement in nanotechnology and nanomedicine has produced an immense drive to find synthesis methods that are green, cost-effective, and controlled. ${ }^{70} \mathrm{With}$ this in mind, Ahmed et al synthesized spherical AuNPs with a crystalline pattern using aqueous extracts of Salicornia brachiata. The $S$. brachiata served as a necessary catalyst in the synthesis process, with only a small amount of extract necessary for the process to proceed quickly. Additionally, this synthesis process requires no capping or stabilizing agents. Antibacterial
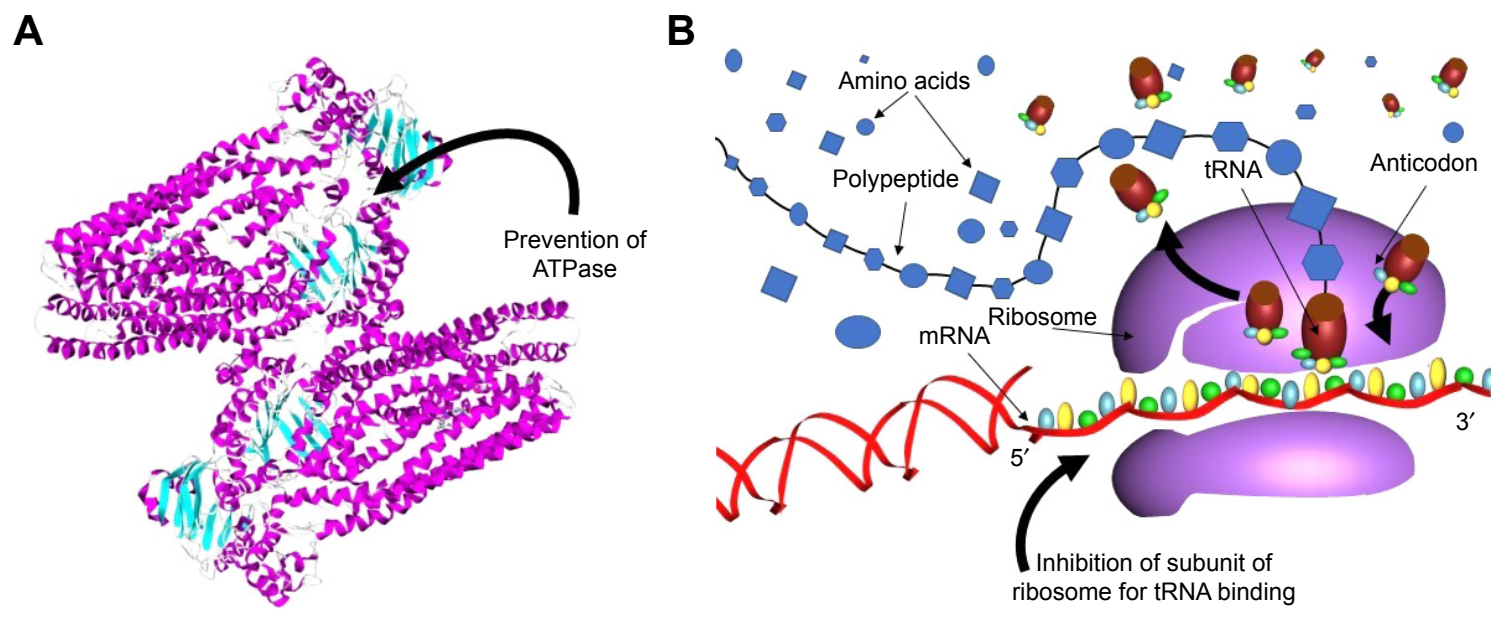

Figure 3 Nanosized gold exhibits antibacterial properties from prevention of ATPase and tRNA binding.

Notes: The antibacterial activities of AuNPs are believed to proceed mainly in the two following ways: (A) a change in the membrane potential and a prevention of ATPase activities leading to a decline in cellular metabolism and (B) the subunit of the ribosome for tRNA binding is inhibited leading to a collapse in biological processes. 
analysis of $S$. brachiata-synthesized AuNPs (SbAuNPs) showed strong antibacterial activity against Pseudomonas aeruginosa, Salmonella typhi, E. coli, and S. aureus. Moreover, the maintained clear appearance of $S b A u N P s$ after a 30-day water submersion suggests a minimal aggregation of the $S b$ AuNPs. With similar goals, Annamalai et al ${ }^{71}$ fabricated AuNPs using the leaf extract of the medicinal plant Euphorbia hirta L. Here, the reduction of gold ions was observed to be catalyzed by the leaf extract and resulted in the formation of stable nanoparticles at a more rapid rate of nanoparticle production when compared to other synthesis methods. Growth inhibition of bacteria cultures was observed to be $88 \%$ for E. coli, $86 \%$ for P. aeruginosa, and $94 \%$ for $K$. pneumonia. The antibacterial effect of resulting nanoparticles at extremely low concentrations of Au was equal to the effect of large amounts of plant material alone, suggesting that the heightened antibacterial effect of E. hirta AuNPs can be attributed to a synergistic effect of the plant extract and gold nanopowder.

Several studies suggest that the inhibition of bacterial growth by AuNPs is highly dependent on the surface area of the nanoparticles. One study suggests that this may be because a high surface area produces $\mathrm{Au}^{3+}$ ions and also plays the role of a reservoir for the $\mathrm{Au}^{3+}$ ions. ${ }^{72}$ In addition to surface area, physicochemical characteristics such as dispersion, shape, and surface capping of the nanoparticles may also affect the antibacterial activity of AuNPs. Zhou et $\mathrm{al}^{14}$ report that the formation of aggregates of AuNPs reduces the surface area, and subsequently, the interaction between the nanoparticle and bacteria. By using weakly bound capping agents, such as citrate, the group reports bacterial inhibitory interactions. However, a strongly bound capping agent (such as PAH) may be used to reduce aggregation and results in AuNPs with better antibacterial performance.

\section{Nanorods}

There is a growing recognition in the engineering of nanomaterials that fabrication of nanostructures, along with their specific physicochemical properties, can regulate the responses of biological entities, such as bacteria. ${ }^{73}$ Therefore, fabrication of gold nanorods (AuNRs) where manipulation of size, dimension, and aspect ratio is possible is imperative in the advancement of applications such as drug delivery and water treatment. Zhu et al ${ }^{74}$ prepared two- and three-dimensional uniform arrays of AuNRs by confined convective arraying techniques and studied the photoheated bacterial effects on E. coli. The resulting AuNRs had an aspect ratio of $\sim 2.5$. Examination of antibacterial activities of 2D and 3D AuNR arrays after their quick and controlled formation was studied on E. coli using laser illumination on nanorod-arrayed substrate. Results showed that $98 \%$ of $E$. coli was photothermally destroyed indicating that this photothermal treatment using AuNR arrays could be promising in water treatment of pathogenic bacteria in the water. This study developed a targeting agent for selectively killing methicillin-resistant Staphylococcus aureus (MRSA) using antiprotein An antibody-conjugated polystyrene sulfonate-coated AuNRs. Results of photothermal therapy resulted in an $82 \%$ reduction in MRSA cells. The study compared the results of applying therapy to healthy muscle tissue and infected muscle using a mice model. Results of in vivo testing of infected mice showed a $73 \%$ bacterial reduction. ${ }^{75}$

\section{Nanocluster}

Gold nanoclusters (AuNCs) possess unique electronic structures with desirable chemical and optical properties. These fluorescent metal nanoclusters are a new class of fluorophore demonstrating promising photostability and biocompatibility. ${ }^{76}$ For example, Yang et $\mathrm{al}^{77}$ developed bovine serum albumin (BSA), histidine (his), and DNA-templated AuNCs for an enhanced fluorescence system based on $\mathrm{Eu}^{+}-$ Tetracycline (EuTC) complex to be utilized as a fluorescent probe. Results demonstrated successful synthesis of BSA/ AuNCs, DNA c12 $_{2} / A u N C s$, and His/AuNCs, although each displayed different patterns in high-resolution transmission electron microscopic images, with His/AuNCs displaying the smallest size of AuNCs. Results for the analysis of three types of AuNCs synthesized showed remarkably enhanced fluorescent intensity with the introduction of $\mathrm{DNA}_{\mathrm{cl} 2} / \mathrm{AuNCs}$ to EuTC of 13 -fold compared to EuTC alone. Utilizing this enhanced fluorescence method may significantly broaden the potential ways to detect tetracycline in actual urine samples thus leading to further biological applications.

\section{Composites}

Composites are being investigated for the synthesis of biomimetic systems encompassing the favorable photoelectric and thermophysical properties of noble metal nanoparticles, while increasing the stability of nanomaterials. ${ }^{78}$ For example, metal oxide nanomaterials have unique capabilities of storing energy by charge separation and creation of electron-hole pairs when exposed to light. $\mathrm{He}$ et al constructed $\mathrm{ZnO} / \mathrm{Au}$ hybrid nanostructures by the photoreduction method resulting in AuNPs of sizes smaller than $3 \mathrm{~nm} .{ }^{79}$ Size and density of AuNPs were controlled and manipulated by modification 
of $\mathrm{HAuCl}_{4}$ concentration during photoreduction; with increasing concentration resulting in an increase in size in lower molar ratios. Enhanced antibacterial activity of $\mathrm{ZnO} / \mathrm{Au}$ hybrid nanostructures showed distinctive $\mathrm{ZnO} / \mathrm{Au}$ dependence when introduced to gram-positive $S$. aureus and gram-negative $E$. coli cultures.

Composites made from polymeric nanofibers, such as CS systems, exhibit biocompatible, biodegradable, and favorable antibacterial properties. ${ }^{80}$ Yan et al studied the fabrication of AuNRs encapsulated within PVA/CS hybrid nanofibers by electrospinning. The chemical structures of PVA and CS were unchanged after the introduction of AuNRs, signifying viability of the system. The PVA/CS and AuNR/PVA/ CS hybrid systems demonstrated low cytotoxicity against human ovarian epithelial cells, indicating biocompatibility of the hybrid system. Researchers have gone further to study systems where utilization of natural cellular membranes in conjunction to gold nanoparticulates has produced nanocomposites with highly tunable physicochemical properties. For example, Gao et al synthesized AuNPs with natural cellular membranes as a new antibacterial biomimetic vaccine strategy. This strategy allows for the manipulation of a desired immune response that may enhance antimicrobial immunity in the host. Bacterial outer membrane vesicles (OMVs) from E. coli were collected and coated onto AuNPs. These specialized bacterial-gold nanoparticles (BM-AuNPs) caused rapid maturation and activation of dendritic cells in the lymph nodes after subcutaneous injection into mice. BMAuNPs elicited specific immunity against the source bacteria in the vaccinated mice. The favorable physicochemical properties of the synthetic AuNPs allow for the manipulation of the size and shape desired for effective antigen presentation to immune cells. ${ }^{81,82}$ With similar goals, Ostdiek et al conjugated an active patch of porcine abdominal aortic decellularized tissue to $100 \mathrm{~nm}$ AuNPs. The active patch was inserted into the thoracic aorta of six pigs and monitored for 6 months. Gross analysis of the patches within the chest showed minimal scar tissue and lack of aggregation of platelets and a coagulation response. Additionally, constructive remodeling was achieved through elimination of possible immune response elements but maintaining the integrity of the ECM. Histological analysis of images showed a lack of macrophages, signaling no chronic/long-term inflammatory response present 6 months after implantation. Incorporating AuNPs to acellular tissue improves the biocompatibility of the system. In addition to gold being biologically inert and exhibiting antibacterial properties, the presence of these nanoparticles promotes fibroblast cell proliferation and delayed degradation of acellular tissue. This study showcases a nanocomposite system of decellularized tissue and AuNPs as promising for vascular repair and blood contacting applications. Moreover, the patches were capable of withstanding the aortic pressure within the five surviving pigs while also promoting cell adhesion and proliferation. ${ }^{83}$

\section{Toxicity}

Toxic effects of gold nanomaterials from induced production of ROS may lead to a reduction in cell viability. Disruption of the cytoskeleton network may also play a role in the cytotoxicity displayed by AuNPs. Alterations to the actin and tubulin cytoskeleton cause cellular stress, leading to a decrease in cell proliferation and differentiation. ${ }^{84}$ Additionally, a comparison between the toxic effects of aggregated and nonaggregated AuNPs suggest that aggregated nanoparticles exhibit less toxic effects. ${ }^{85}$ Although AuNPs demonstrate a significant toxic effect against many cell types, effects on dendritic cells were not significant, regardless of increasing gold nanoparticle concentration. Since dendritic cells play an important part in initiating a specific immune response, it is good that AuNPs do not show toxicities among the cells. ${ }^{86}$

The toxicity of gold nanoparticles on the environment, including toxic effects in plants and animals, is currently under investigation. In an in vivo experiment conducted using a mice model, mice were given a weekly injection of $8 \mathrm{mg} / \mathrm{kg}$ of AuNPs (ranging in size from 3 to $100 \mathrm{~nm}$ ). Although nontoxic nanoparticles were administered to the mice, results showed the injections to have lethal effects on the majority of the animals tested. These results are concerning since they are indicative of the lethal effect seemingly nontoxic AuNPs may have on mammals. ${ }^{87}$ Another study involving maize elucidates the possible toxic effects gold nanomaterials might impart on feed and food crops. In the study, high concentrations of AuNRs (ie, 350, 5.8, and $14 \mathrm{mg} / \mathrm{L}$ ) were placed surrounding the roots of maize. The AuNRs were found to accumulate in the roots and leafs of the maize plants and to physically interfere with uptake pathways. The results also showed an inhibition in plant growth and in the nutritional absorption of the plants. Lower concentrations of AuNRs of $4.5 \times 10^{-3}, 0.45$, and $2.25 \mathrm{mg} / \mathrm{L}$, during a 10-day exposure, however, showed biocompatibility. The authors suggest that the correlation between the amount of gold nanomaterials with the level of toxicity may be used to increase control over the toxic effects of AuNRs. ${ }^{88}$

Cytotoxic effects of AuNPs against cancer cells are reported to be dependent on the morphology and surface chemistry of the nanoparticles. In a study conducted to 
evaluate the anticancer activity of AuNPs, doses of 6.25$100 \mu \mathrm{g} / \mathrm{mL}$ were introduced to human breast cancer cells MCF-7. ${ }^{89}$ Results suggest that spherical $25 \mathrm{~nm}$ AuNPs show the optimal cytotoxicity to the cancer cells at a concentration of $100 \mu \mathrm{g} / \mathrm{mL}$. Although the lack of aggregation of the uniformly dispersed, spherical nanoparticles is attributed to the anticancer properties of the synthesized nanoparticles, the exact effect of these morphological properties on cytotoxicity is not understood and should be further investigated.

\section{Summary}

Gold nanomaterials display favorable antibacterial properties that can be controlled by selectively fabricating these into the desired size and structural shape. AuNPs are believed to exert antibacterial behavior by causing a change in membrane potential, preventing ATPase, and inhibiting the subunit of ribosome for tRNA. Additionally, increasing the aspect ratio of gold nanostructures allows for utilization of gold's optical properties to work in combination with its bactericidal activity. When fabricated into nanorods, lasers can be used to photothermally reduce the number of viable bacterial cells by $\sim 98 \%$. An increase in the aspect ratio also increases the stability of the produced nanostructure, allowing for proteins or conjugated molecules to attach and suggesting a feasibility for a range of biological applications, including targeted drug delivery and fluorescence identification. For example, when developed into nanoclusters, gold nanostructures can serve as fluorophores due to their photostability and show a largely enhanced fluorescent intensity compared to nongold nanocluster containing controls. Furthermore, these nanoclusters may be synthesized to display different patterns, although further investigations on reliable synthesis techniques are needed. Composites using gold nanomaterials increase the stability of the nanosystems while maintaining the favorable optical and thermal physical properties of the noble metal nanostructures.

\section{Copper nanomaterials}

The element copper has been used in ornaments, weaponry, and coinage since early into the 14 th century. Copper coinage was originally developed in what is now known as Turkey and Iraq, and soon spread to Spain, Europe, and Sweden. Symbolically, copper was used to mark the beginning of womanhood, consecrate kings, and propitiate ancestors or gods.$^{90}$ After the 1850 s, copper began its use in electrical wiring. For example, copper was laid across the Atlantic as a telegraph cable in 1866 and used as telephone wire that allowed for communication across larger distances. At the turn of 20th century, copper began to be used in applications within the service activities. ${ }^{91}$ Since then, copper has been important in research because of its role in living organisms. A copper deficiency in the human body can lead to anemia and improper fetal development during pregnancy. On a smaller scale, it plays an important role in the transportation of oxygen during the electron transport chain and iron homeostasis. Shortly after reports identified copper as an antibacterial reagent, ${ }^{92}$ synthesis techniques for producing nanosized copper were developed. ${ }^{93}$ It has been reported that the antibacterial characteristics displayed by copper are a result of cellular damage after contact between released $\mathrm{Cu}^{2+}$ ions and bacteria membrane.

This section analyzes different synthesis, antibacterial properties of the structure nanoparticle, comparison of different shapes and sizes, promising composites, and toxicity properties of copper nanomaterial.

\section{Nanoparticles}

Copper nanoparticles (CuNPs) are excellent antibacterial reagents due to their heat resistance and chemical stability. This may be attributed to a large surface area to volume ratio, which allows CuNPs to penetrate microbial membranes. CuNPs can be synthesized through several techniques including chemical reduction, laser ablation, sol-gel processing, and thermal reduction - each resulting in CuNPs displaying varying antibacterial properties. ${ }^{94}$

CuNPs made through different synthesis techniques display varying antibacterial properties. Modifications to classic synthesis techniques, such as the modified polyol method reported by Ramyadevi et al, can favorably affect antibacterial properties of CuNPs. Using the modified polyol method by reduction of copper acetate hydrate showed antimicrobial activity in both bacterial and fungal strains, with different amounts of antibacterial activities observed due to stain. ${ }^{94}$ External stimulation, such as exposure to UV radiation during synthesis, may also increase the antibacterial activity of resulting CuNPs. Veerapandian et a ${ }^{95}$ synthesized hybrid glucosamine functionalized copper nanoparticles (GlcNCuNPs) and reported higher in vitro antibacterial activity against two gram-negative and two gram-positive bacteria compared to GlcN-CuNPs not exposed to UV radiation. ${ }^{95}$

Due to copper's antibacterial performances, CuNPs can be used for several applications. As an antibacterial composite in food packaging, CuNPs inhibit bacterial growth. Gram-negative microbial group of Pseudomonas spp. is a common strain seen proliferating in processed food and naturally develops a resistance to common antibiotics. CuNPs embedded in a polylactic acid matrix are promising toward 
preventing bacteria proliferation of Pseudomonas spp. ${ }^{96}$ Against urinary tract pathogen, copper oxide nanoparticles (CuONPs) have shown antibacterial performance. Tabernaemontana divaricata leaf is an Indian medicinal plant with proven anti-inflammatory and antibacterial properties. Biogenic CuONPs synthesized using $T$. divaricata leaf extract are promising against urinary tract infection. ${ }^{97}$

Investigations into interactions between CuONPs and CuNPs against bacteria suggest that CuNPs inhibit bacterial growth more successfully. Varying concentrations of CuONPs show successful inhibition of bacterial growth, with a greater concentration in CuONPs showing a higher bacterial inhibition. Possible reasons include a more direct interaction between the CuNPs and the bacteria strain, leading to more penetration and rupture of the bacterial membrane. Cellular membrane disruptions can lead to cell enzyme malfunction and eventually cell death. ${ }^{98} \mathrm{CuNPs}$ display greater antibacterial activity than CuONPs, which may be attributed to a better electron transfer between the bacteria and CuNPs. The slightly negative bacteria and the metallic nanoparticles act as good electron acceptors, both contributing to the electron transfer and rupture of the bacteria membrane. Also, light irradiation can lead to excited electron-holes pairs in $\mathrm{CuO}$, which show that the bacteria's inactivation could be mostly due to a photocatalytic process. Overall, CuNPs still showed a stronger antibacterial performance compared to CuONPs made by sol-gel on thin silica films, which is predicted to be due to a better electron transfer. ${ }^{99}$ Poly-L-lysine/reduced graphene oxide/copper nanoparticles (PLL-rGO-CuNPs) hybrid show antibacterial performances for long term. Reduced graphene oxide (rGO) has shown significant antibacterial activity, which may be due to its GNS' sharp edges. The interaction with this material results in cell damage, loss of cell membrane integrity, and RNA leakage. ${ }^{100}$

During copper nanomaterial production, thermal treatment, the size of films, and a number of nanomaterials are factors that may affect antibacterial levels. In regard to $\mathrm{CuONPs}$ - silica films, an increase in temperature from $400^{\circ} \mathrm{C}$ to $600^{\circ} \mathrm{C}$ and reduction in the thin films reduced the antibacterial activity. The reduction can be due to the thermal reduction of CuONPs to $\mathrm{Cu}$ and/or a decrease in copperbased particles on the surface of the films. ${ }^{99}$ Applications of nanoparticles include food delivery of drugs, genomics, and cancer cell photothermolysis. ${ }^{101}$

\section{Comparison of shapes and structures}

Fabrication of copper nanomaterials of different dimensions demonstrates varying levels of antibacterial performance.
The antibacterial effects exhibited by $\mathrm{CuO}$ nanomaterials in the particle (grain like), tube (needle like), and plate structures (Figure 4) were investigated against gram-positive bacteria Streptococcus iniae and Streptococcus parauberis and gram-negative bacteria E. coli and Vibrio anguillarum. An increase in the release of copper ions was observed in plate-like $\mathrm{CuO}$ nanomaterials compared to the grain-like and needle-like-shaped $\mathrm{CuO}$ nanomaterials. Factors that could contribute to the observed antibacterial effects due to dimension and structure of $\mathrm{CuO}$ nanomaterials include the amount of surface area for adsorption or desorption and damage leading to tearing of bacterial cells. Such damage occurs by an initial release of copper ions that bind onto the double helix of DNA. The bacterial cell consequently dies, following a biochemical process or from the damage sustained to DNA molecules. ${ }^{102}$

Similarly, the size and dimensions of nanocrystal structures influence the antibacterial effects demonstrated by these nanostructures. Hassan et al observed an increase in bacterial inhibition with an increase in $\mathrm{CuO}$ nanocrystal concentration. Factors contributing to the bacterial cell damage include oxidative stress caused by the release of $\mathrm{Cu}$ ions and rapid anaerobiosis. The production of ROS from the $\mathrm{CuO}$ nanocrystals may begin with the reduction of $\mathrm{O}_{2}$ and synthesizes of superoxide anion $\mathrm{O}_{2}^{-} \cdot$. These ROS then come into contact with the cellular membrane, generating free radicals that will enter the cell and cause disruption of the cell's internal content. Ultimately, such disruption by ROS causes leakage to the bacterial cell. ${ }^{103}$

Alignment of nanostructures may also affect the antibacterial properties of the resulting nanostructure. For example,

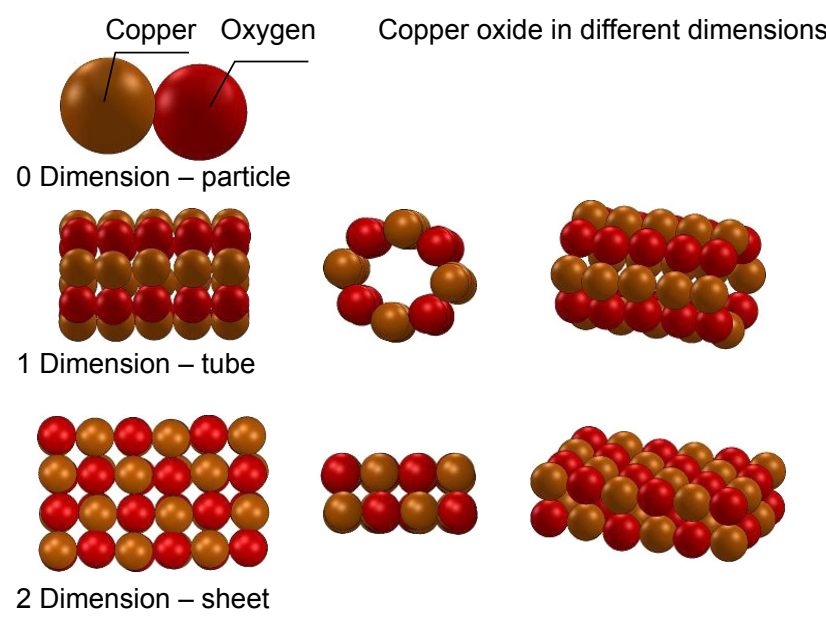

Figure 4 Copper oxide dimensions.

Notes: Different copper oxide dimensions produce different amounts of antibacterial properties due to their ratio of surface area to volume. The simplest structure is a particle, then tube, followed by the sheet. 
using the method of template-based electrodeposition, where nanotubular $\mathrm{Cu}$ arrays (NT-Cu) are vertically aligned, levels of antibacterial activities are different compared to unaligned NT-Cu. This is attributed to the structure of vertically aligned NT-Cu possessing a high ratio aspect and ultrafine pores in comparison to other structures. ${ }^{104}$

\section{Promising composites}

Dissolution of CuNPs from copper nanocomposites results in favorable high antibacterial behavior. For example, TaN-Cu nanocomposite thin films where CuNPs lay on the surface of TaN resulted in a galvanic effect. Because of the galvanic effect, when the CuNPs came into contact with TaN films, there was a higher rate of dissolution. This implies that the particle size and density affect the antibacterial activities. $\mathrm{TaN}-\mathrm{Cu}$ nanocomposite thin films showed antibacterial properties due to the copper ions that will dissolute. Positively charged copper ions come into contact with negatively charged cell walls of the bacteria, which leads to damage of the cell walls and cell death. ${ }^{105}$ Aside from the dissolution of copper particles, production of ROS also causes antibacterial activities. For example, copper iodide nanoparticles can act as an antibacterial agent against gram-negative and grampositive bacteria, due to ROS production. ROS normally leads to DNA damage, as observed when CuNPs were introduced to bacterial strains of DH5(alpha) and B. subtilis. ${ }^{101}$

\section{Toxicity}

In regard to certain metals such as copper, the toxicity of nanometal oxides is attributable to the soluble metal ions from the material. The solubility of nanometals is an important factor for its toxicity. In comparison of CuONPs that are more soluble than bulk $\mathrm{CuO}, \mathrm{CuONPs}$ are more toxic. Against algae, CuONPs are toxic at sub milligram/liter concentration, due to the release of copper ions. ${ }^{106}$ However, the number of copper ions released by the CuONPs was independent of nanoparticle size. Comparison of bulk and CuNPs has shown a greater toxicity for CuNPs due to a larger surface area-to-volume and increased reactivity, with smaller CuNPs displaying higher toxicity compared to their larger counterparts. ${ }^{107}$ Size-dependent toxic effects of CuNPs allow for the control of toxicity. Copper nanoparticles are seen to be more toxic than larger copper nanoparticles in zebra fish. However, copper submicron-sized particles of $400 \mathrm{~nm}$ were more toxic than copper nanoparticles. ${ }^{108}$

There is evidence of the toxic effects of CuNPs in the environment. The activity of the dissolved copper ions in the presence of micrometer-sized $\mathrm{CuO}$ (Figure 5A) was less than in the presence of CuONP (Figure 5B). ${ }^{109}$ Additional studies suggest evidence of concentrations of $\mathrm{Cu}^{2+}$ in soil organisms, such as earthworms ${ }^{110}$ and white worms ${ }^{111}$ from CuNPs. Even among plants, a greater root toxicity is present with small CuNPs compared to larger sizes. Metal oxide particles show
A

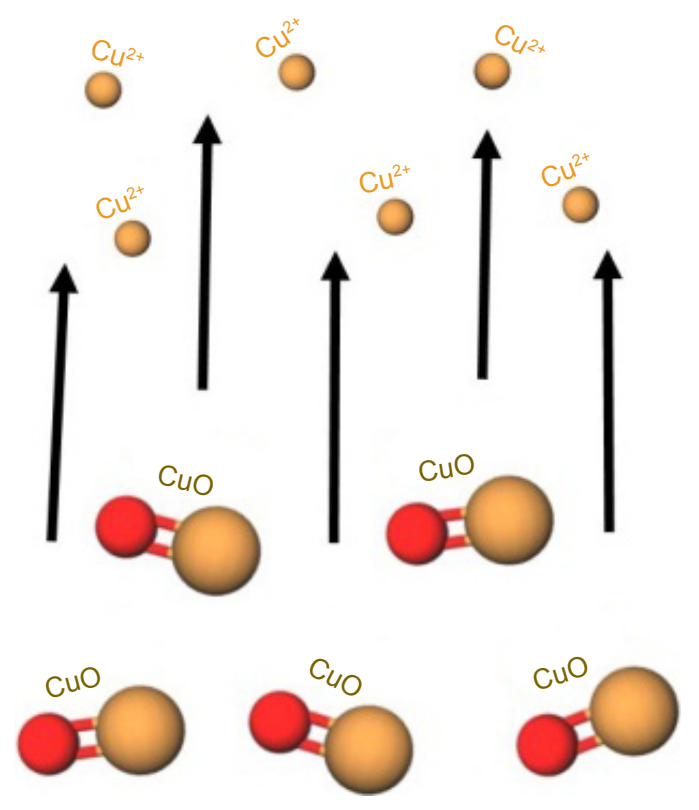

B

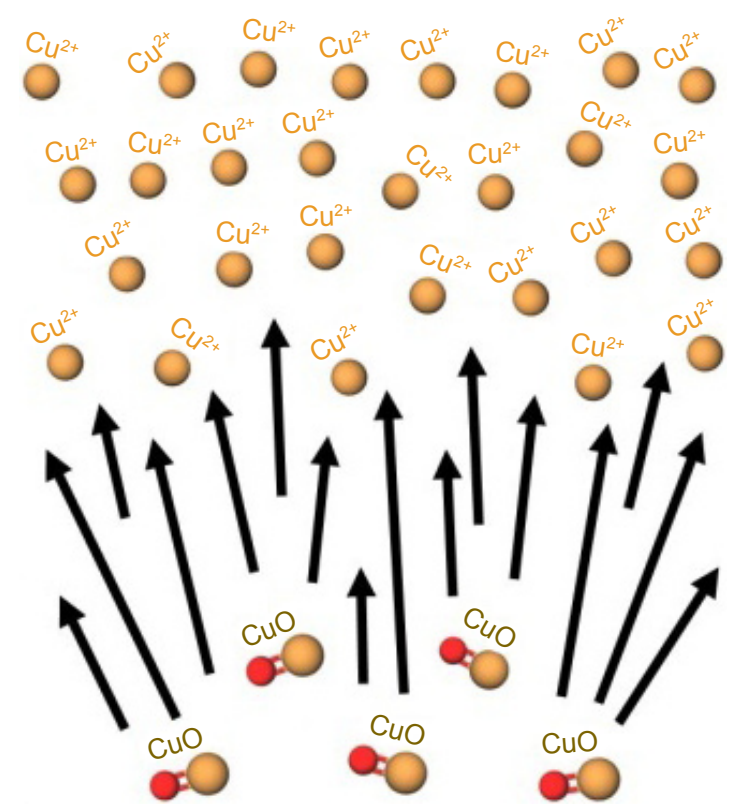

Figure 5 Comparison of released toxicity from microsized vs nanosized copper oxide.

Notes: Due to the differences in the ratio of surface area to volume, toxicity levels are dependent on the size of copper oxide. Smaller structures such as (B) nanosized copper oxide compared to (A) microsized produce larger amounts of copper ions. The amount of toxicity is dependent on a number of copper ions released. 
increased toxicity correlating with smaller sized particles. ${ }^{112}$ Among cells, high concentrations of CuNPs have been shown to lower cell mortality. However, the mechanism of action for the toxic effects exhibited by CuNPs can occur through alternative methods, including the dissolution of ions from copper. ${ }^{113}$ Against algae cells, neither chemical analysis nor biological testing has confirmed cupric ions in toxic amount. Since death of algal cells is observed with low amounts of $\mathrm{Cu}^{2+}$, the dissolution of ions is believed to be a partial factor in CuNP toxicity. ${ }^{114}$

\section{Summary}

Copper on a nanoscale has been observed to be a promising antibacterial agent. Based on the dimension of the nanomaterial, different levels of antibacterial performances will be exhibited. In a comparison of grain-like, needle-like, and plate-like shapes, the structure of plate-like copper nanomaterials showed the most promising antibacterial activities due to factors such as a large surface area and release of copper ions. Certain composite with copper also shows a significant amount of antibacterial activities such as $\mathrm{CuO}$ nanomaterial and CuNPs embedded in polylactic acid. Methods for composing the nanomaterials include using laser ablation, sol-gel processing, coprecipitation, chemical reduction, microwave irradiation, and others. Antibacterial studies show that copper nanoparticles produce ROS against bacteria, leading to DNA damage. Because of the significant antibacterial performances of copper, the element has been used for applications, including drug delivery, antibacterial composite food packaging, and water filter treatment.

\section{Titanium nanomaterials}

Application of titanium in the biomedical field started in the early 1940s when laboratory animals were used to test titanium implants. In 1959, two American researchers explored the idea of using cast titanium to make implant posts. ${ }^{15}$ Soon after, titanium became popular in the field of dentistry, which led to the first titanium cast for dental prostheses in $1977 .{ }^{115}$ Since then, use of orthopedic implants has steadily increased for both internal and external fixation and prostheses. However, despite sterilization techniques, infections remain the main cause of implant failure. Because of the success of elemental titanium in the dentistry and orthopedic fields, titanium nanomaterials are now being investigated as antibacterial reagents. This section will examine the effect of different synthesis techniques of titanium nanomaterials on their exhibited antibacterial properties. We will also discuss the unique crystal structures of titanium and their antibacterial properties due to photocatalytic activities.

\section{Synthesis}

Synthesis of $\mathrm{TiO}_{2}$ nanostructured layers in organic viscous electrolytes has shown antibacterial behaviors. Electrochemical anodization method obtains metal oxides at a nanoscale, while also being easy and cost-effective. Control of electrochemical conditions affects morphology, making it easy to make nanoporous self-organized nanotubular $\mathrm{TiO}_{2}{ }^{116}$ Other methods have been seen promising such as nano$\mathrm{TiO}_{2}$ synthesized by liquid hydrolysis under light which has shown promising antibacterial activities. The method of liquid hydrolysis is cheap and simple compared to the solgel method, which is expensive, and precipitation method, which is cheap, but is time-consuming and produces low purity products. ${ }^{117}$

Control of titanium surfaces such as crystallinity, nanotube size, and chemistry affects responses toward bacteria strains, such as $S$. epidermidis and $S$. aureus. Additionally, levels of antibacterial performances are influenced by the diameter of titanium nanotubes, with TiNTs of an $80 \mathrm{~nm}$ diameter showing the most antibacterial activity. Therefore, controlled anodized Ti nanotube diameter size formation is important toward promising amounts of antibacterial performances, which can be applied to improved antimicrobial behavior and tissue growth properties. ${ }^{118}$ Aside from diameters, under a solar-simulated light, double-doped $\mathrm{TiO}_{2}$ nanoparticles $\left(\mathrm{TiO}_{2} \mathrm{NPs}\right.$ ) have acted as a visible lightactive antibacterial agent. Using sol-gel method, doubledoped $\mathrm{TiO}_{2} \mathrm{NPs}$ exhibited the most antibacterial activity in comparison to single-doped $\mathrm{TiO}_{2} \mathrm{NPs}$ under visible light irradiation. This can be due to the attribution of two different electronic states that act as electron traps in the $\mathrm{TiO}_{2}$, which is responsible for a narrower band gap and therefore shifts the optical response from the region of UV into visible light. Due to this significant antibacterial performance of double-doped instead of single-doped $\mathrm{TiO}_{2} \mathrm{NPs}$, this extra step can lead to further biomedical application for a decrease in infection and bacterial count. ${ }^{119}$

\section{Crystal structures}

The three crystal structures of nano- $\mathrm{TiO}_{2}$ include anatase (Figure 6A), brukide (Figure 6B), and rutile (Figure 6C). Among the three crystal structures, anatase has the most antibacterial activity. Under temperatures of $600^{\circ} \mathrm{C}-700^{\circ} \mathrm{C}$, anatase structures produce $\bullet \mathrm{OH}$ in a photocatalytic reaction, puncturing the bacterial wall and killing the bacteria. ${ }^{117}$ 

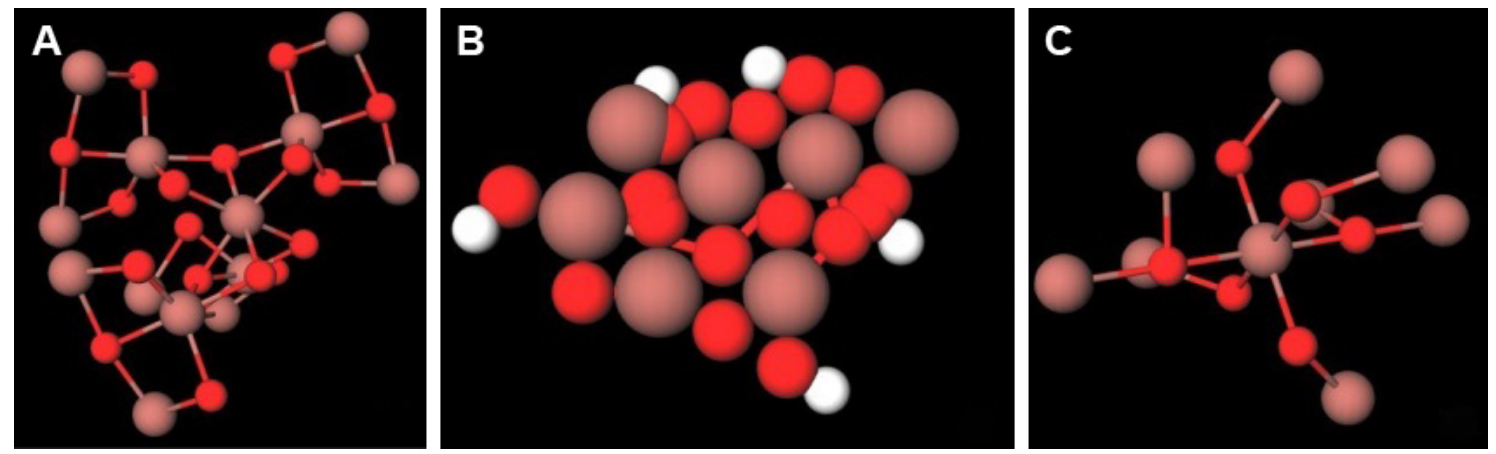

Figure 6 Titanium dioxide crystal structures.

Notes: The three crystal structures of titanium dioxide show different amounts of antibacterial properties due to its production of $\bullet \mathrm{OH}$ in its photocatalytic reaction, which causes cellular damage. (A) Anatase compared to other crystal structures such as (B) Brukide and (C) Rutile shows the most antibacterial activity.

The presence of light is important to the antibacterial properties exhibited by titanium. To examine the effects of light on the antibacterial properties of $\mathrm{TiO}_{2}$ nanomaterials, antibacterial activity was compared at varying concentrations. Although an increase in nano- $\mathrm{TiO}_{2}$ concentration may lead to an increase in bactericidal performance, antibacterial activity was reported to decrease at a concentration of $0.8 \mathrm{~g} / \mathrm{L}$. This observation suggests that with an increase in nano- $\mathrm{TiO}_{2}$ concentration, there is also an increase of contact with the bacteria. When the concentration is larger than $0.8 \mathrm{~g} / \mathrm{L}$, however, the nano- $\mathrm{TiO}_{2}$ has less contact with light, resulting in a decrease in photocatalytic activity, as well as its antibacterial effects. It is important to note that an increase in temperature changes the anatase structure into rutile, deteriorating the photocatalytic activity.

\section{Photocatalytic effects}

The antibacterial properties of nanoscaled titanium are due to its photocatalytic properties. These properties completely decompose contaminants and kill microbes under UV light irradiation. The positively charged nanomaterials affect bacterial growth and viability by changing the permeability when the nanomaterial interacts with negatively charged lipid membranes of bacteria, blocking nutrient intake. Bacteria is also killed by high ROS produced by the photocatalytic process of $\mathrm{TiO}_{2}$, such as hydroxyl radical, superoxide, or hydrogen peroxide. ${ }^{120}$ As a photocatalyst, titanium dioxide both oxidizes organic contaminants and damages microbial cells. Significant antibacterial performances are light activated from the nanomaterial of $\mathrm{TiO}_{2}$ nanoparticle-based film. ${ }^{121}$ Another example of its photocatalytic properties is from nanostructured titania $\left(\mathrm{nTiO}_{2}\right)$. Its antibacterial activities are due to the photocatalytic effect of $\mathrm{nTiO}_{2} / \mathrm{PU}$ nanocomposite film when irradiated under solar illumination (Figure 7A). The $\mathrm{nTiO}_{2} / \mathrm{PU}$ composite produces $\mathrm{OH} \bullet$ radicals that damage bacterial cells because of a decrease in coenzyme A (CoA), a mediator of electron transport between the cell and $\mathrm{nTiO}_{2}$. Without solar illumination, neither pure $\mathrm{PU}$ film nor $\mathrm{nTiO}_{2} / \mathrm{PU}$ nanocomposite film demonstrates any antibacterial activities against the E. coli (Figure 7B). A control experiment using the pure PU film under solar illumination for 50 minutes showed only a slight activity in antibacterial performances. Using the "grafting from" polymerization method to make $\mathrm{nTiO}_{2} / \mathrm{PU}$ composite coatings, under solar irradiation almost all the bacteria were killed within 50 minutes due to $\mathrm{nTiO}_{2}$ 's photocatalytic effect. This antibacterial observation of $\mathrm{nTiO}_{2} / \mathrm{PU}$ composite coatings has significance for outdoor application to prevent undesired bacteria from growing. ${ }^{122}$ Factors that contributed to the differences in amount of antibacterial activities include small average particle size, surface chemical state, high surface area, large band gap, structure and size distribution of pore. ${ }^{123}$

\section{Toxicity}

Titanium nanomaterials exhibit lower toxicity than other nanometal oxides. As nanoparticles, nano- $\mathrm{ZnO}$ was found to be the most toxic at sub milligram/liter concentrations, followed by nano- $\mathrm{CuO}$ and finally nano- $\mathrm{TiO}_{2}$. The toxic effects of nanosized $\mathrm{TiO}_{2}$ are reported to result from the entrapment of cells, rather than from the dissolution of metal ions, as is reported in a study involving algae Pseudokirchneriella subcapitata. ${ }^{106}$ Even though toxicity of nanotitanium can be useful against unwanted bacterial growth, toxicity level can be lowered to use the material for implants within the body without compromising the viability of cells. Manipulation of shape and length changes toxicity levels, making the material a better bactericidal reagent that will not harm the body. The composite nanotrititanate has the same bactericidal effects, despite changes in shape and length when compared 
A

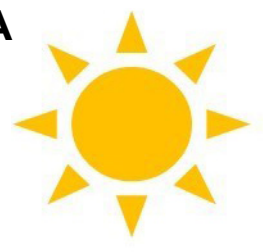

Light illumination

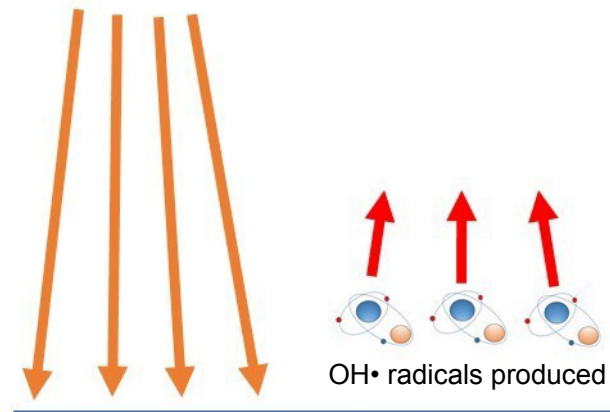

Nano- $\mathrm{TiO}_{2} /$ polyurethane composite film
B

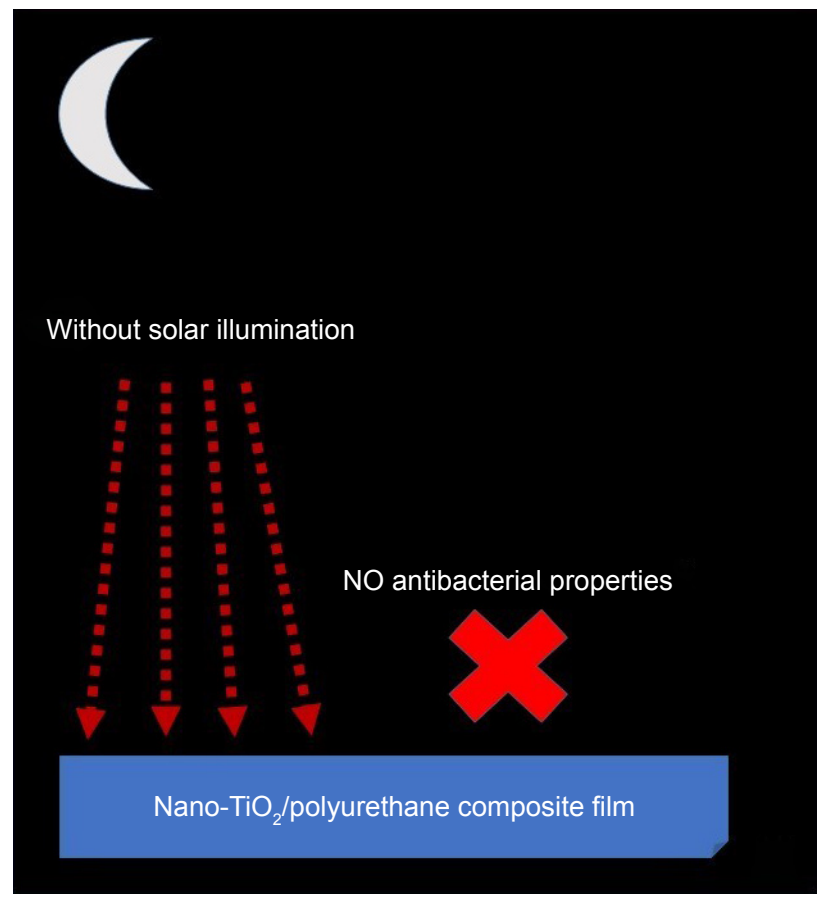

Figure 7 Antibacterial activities due to titanium dioxide illumination. Nanotitanium dioxide produces antibacterial properties when (A) light illumination is present due to released hydroxyl radicals which cause cellular damage. (B) Without illumination of any kind, no antibacterial properties are produced.

with unchanged dimensions. However, changes in dimensions from nanotubes to nanoplates were able to lower the toxicity, and study found that titanium nanoplates showed the lowest toxicity to HEp-2 cells. ${ }^{124}$

Nano- $\mathrm{TiO}_{2}$ is reported to be toxic to many aquatic organisms such as fish, cyanobacteria, and algae. However, in relevance to benthic microbial communities which are key components of freshwater habitats, not much is known about the results of added nano- $\mathrm{TiO}_{2}$. Benthic bacterial communities contribute to the ecosystem process such as with their primary production, decomposition of organic material, nutrient cycling, and pollutants bioremediation. In a study of its effects on artificial stream communities, a single addition of nano- $\mathrm{TiO}_{2}$ with a concentration of $1 \mathrm{mg} / \mathrm{L}$ demonstrates a rapid decrease in bacteria activity, with a return of bacterial abundance at control level within a period of 3 weeks. The significant decrease in bacterial cell count due to an addition of nano- $\mathrm{TiO}_{2}$ in artificial streams for a short period of time demonstrates the antibacterial performance of nano- $\mathrm{TiO}_{2}$. This study is a good model of the effects nano- $\mathrm{TiO}_{2}$ could have on bacterial cells in wastewater. ${ }^{125}$

Toxicity observations due to nanotitanium have been tested on live animals. Single low doses of nanoanatase $\mathrm{TiO}_{2}$ particles in ICR mice's abdominal cavity, once a day for 14 days, have shown little differences in comparison to control mice. Higher doses, however, showed damages seen in the kidney, liver, myocardium, blood sugar level, and lipids level. ${ }^{126}$ However, in regard to rat's tissues, single injections of $10 \% \mathrm{TiO}_{2}$ concentration in distilled water or silicone demonstrate no significant changes or toxic effects. Health and behavior of the rats were normal while no detectable levels of $\mathrm{TiO}_{2}$ were found in the blood cells, lymph nodes, plasma, or brain. These low doses of $\mathrm{TiO}_{2} \mathrm{NPs}$ are safe due to no detectable organ toxicity, long-term changes within the rat's bodies, and no changes in inflammatory response. ${ }^{127}$ In other animals, low toxicity exposures of $10-40 \mu \mathrm{g} / \mathrm{mL}$ for less than 60 days have also been studied, such as the Chinese hamster. Ovary cells of Chinese hamster have no cyto- or genotoxic effects, adaptable to chronic exposures, and detoxify excess ROS. ${ }^{128}$ Among other animals such as the zebra fish, there have been seen the amount of toxicity from nano- $\mathrm{TiO}_{2}$, which are due to its generated $\bullet \mathrm{OH}$ radicals. In comparison to bulk particles suspensions of 128-949 nm diameters, nanoparticles suspensions of 20-70 nm diameters showed higher levels of toxicity even with similar size distributions. Toxicity mechanism comes from oxidative effects or lipid peroxidation from generated $\bullet \mathrm{OH}$ radicals. ${ }^{129}$ Depending on the location of injection, doses, and type of animal, nanotitanium shows different toxicity levels.

An increase in the usage of titanium in everyday environments has led to pressure on legislators to have tighter 
environmental standards among industries to help inform the public on its safety. ${ }^{130,131}$

\section{Summary}

Due to the antibacterial activities of titanium as a nanomaterial, it is a promising material in the industries for a reduction in bacteria growth and medical field for the decrease in infections. Antibacterial activities by titanium are due to the photocatalytic reaction when under solar illumination or exposure to light, which produces $\bullet \mathrm{OH}$ that would puncture the bacterial cell, leading to the death of bacteria. In the medical field, titanium has been used because of its mechanical properties and biocompatibility. The combination of antibiotics and nanotitanium is promising materials in regard to decreasing infections and bacterial growth in orthopedic implants and other medical applications. ${ }^{131}$ In industries, titanium on a nanoscale is used for its antibacterial activities such as long storage of wool which would have bacterial growth due to moist environment. ${ }^{132}$ Titanium as a nanomaterial is promising in both the medical field and industries due to its antibacterial performances. Toxicity studies are important to daily life such as sunscreen and cosmetics products, toxicity studies are important to prevent biological harms to the body. Different levels of toxicities are seen due to certain locations of injections or exposures, different amounts, and type of animal tested on.

\section{Zinc nanomaterials}

Zinc $(\mathrm{Zn})$ and its alloys have been used extensively in biomedical applications due to their abundance and low toxicity. ${ }^{133}$ These materials have shown promise in biosensing, imaging, and drug delivery due to their electrical, optical, and photocatalytic properties. Recently, the incorporation of $\mathrm{Zn}$ into biomedical devices and bioceramics has increased. One reason for the addition of zinc into biomedical devices is its importance in several biological functions including DNA synthesis and nucleic acid metabolism and because it is known to be an important trace element in human bone. ${ }^{134}$ Additionally, Zn-containing nanomaterials have been reported to exhibit excellent antibacterial qualities. Although zinc has been successfully incorporated into materials using techniques, such as plasma electrolytic oxidation, the most commonly studied zinc-containing nanomaterial is zinc oxide nanoparticles.

Zinc oxide $(\mathrm{ZnO})$ nanomaterials are unique in possessing semiconducting and piezoelectric properties, in addition to exhibiting biocompatible and biodegradable features. Although the mechanism through which more complex
Zn-containing nanomaterials produce antibacterial effects remains largely unknown, the most supported toxicity mechanisms of zinc oxide nanoparticles (ZnONPs) are thought to result from ROS generation and $\mathrm{Zn}^{2+}$ release. ROS, such as superoxide anion, hydrogen peroxide, and hydroxide, can damage lipids and proteins once inside the bacterial cell membrane, while the release of $\mathrm{Zn}^{2+}$ from $\mathrm{ZnONPs}$ can disrupt important metabolic pathways. ${ }^{135}$ Because synthesis techniques and resulting morphology of $\mathrm{ZnO}$ nanomaterials can impact their antibacterial properties, current research efforts are focused equally on developing novel synthesis methods and application.

Advancements in synthesizing techniques of ZnONPs include using precursors (coordination polymers and biological extracts). By using ultrasound radiation, Fard et $\mathrm{al}^{136}$ synthesized $\mathrm{ZnONPs}$ from two zinc(II) coordination polymers. The simple and controlled process resulted in ZnONPs without significant impurities and good crystallinity, but with nonhomogeneity in nanoparticle size. Meanwhile, Thatoi et al synthesized ZnONPs using mangrove plant extracts. ${ }^{137}$ The nanoparticles produced from the Sonneratia apetala mangrove plant exhibited relatively higher antibacterial capabilities, as well as antiinflammatory properties.

Investigations into discovering additional applications for ZnONPs have progressed significantly in dental prosthetics and anticancer treatments. Ciereh et al suggest ZnONP-modified acrylic glass as a promising material for dentures. By combining ZnONPs and acrylic glass, or polymethylmethacrylate (PMMA), the group observed inhibition of fungal biofilm formation that could treat conditions such as denture stomatitis. ${ }^{138}$ After several reports of $\mathrm{ZnONPs}$ exhibiting selective toxicity toward cancer cells surfaced, Akhtar et a ${ }^{139}$ report the selective killing of cancer cells to induce apoptosis after exposure to ZnONPs. The group suggests induced apoptosis of human cancer cells to result from the production of tumor suppressor protein $\mathrm{p} 53$.

\section{Magnesium nanomaterials}

Magnesium (Mg), similarly to $\mathrm{Zn}$, is an abundant metal that is biocompatible, biodegradable, and capable of inhibiting bacterial growth. ${ }^{140}$ Due to its significant presence in bone, and its suspected role in increasing osteoblast activity, it is now being investigated for orthopedic implants. ${ }^{141}$ Nanosized $\mathrm{Mg}$ and its alloys have been reported to exhibit antiinflammatory and antioxidant activity. ${ }^{142}$ A few common mechanisms, including ROS generation, have been proposed 
to explain the antibacterial mechanism of magnesium oxide nanoparticles (MgONPs). However, the exact mechanisms remain unknown. Recent studies into Mg-containing nanomaterials include MgONPs for orthopedic implant coating and fabrication of $\mathrm{MgO}$-containing nanocomposites as scaffolds for bone tissue regeneration. Wetteland et al ${ }^{143}$ report possible guidelines for MgONP-coated biomaterial design. The study showed a significant increase in bone marrowderived mesenchymal stem cells and antibacterial activity when exposed to $200 \mu \mathrm{g} / \mathrm{mL}$ of MgONPs. By adding MgONPs to polycaprolactone hydroxyapatite (PCL/Hap) composites, Roh et al reports enhanced adhesion, proliferation, and differentiation of preosteoblasts. ${ }^{144}$ These results propose possible improvements to 3D-scaffolds for encouraging bone tissue regeneration.

\section{Conclusion and future directions}

Reports of antibacterial activity in nanomaterials have stemmed from observed biophysical interactions occurring between nanoparticles and bacteria, including cellular uptake and nanoparticle aggregation, leading to membrane damage and toxicity. ${ }^{14}$ In particular, metallic nanomaterials (such as silver, gold, copper, and titanium) exhibit favorable physicochemical characteristics resulting in significant levels of antibacterial activity. This review has focused on the recent advancements made in metallic nanomaterials as antibacterial agents, with a focus on their toxicity and antibacterial activity based on the structure, dimension, and size of nanomaterial. Furthermore, it has also discussed the benefits of using nanomaterials of silver, gold, copper, titanium, zinc, and magnesium metals in biomedical applications. A summary of the antibacterial properties exhibited by each nanomaterial is shown in Table 1.

However, with such advances comes new needed regulations and restrictions. Although most manufactured nanomaterials are dispersed readily when in contact with water ${ }^{144}$ there are some exceptions. For example, metallic nanotubes are not dispersed in water, even with the use of physical methods. Due to the nondispersing properties, potential harmful nanomaterials will contaminate resources that could interact with humans, animals, and the environment. Therefore, future prospects should focus toward establishing new regulations that should result from thorough chemical and toxicological characterization of fabricated nanomaterials. Furthermore, ecotoxicity tests should be set into place when considering any applications directly involving humans and other living organisms. As studies move from in vitro to in vivo experiments, regulations need to be set on

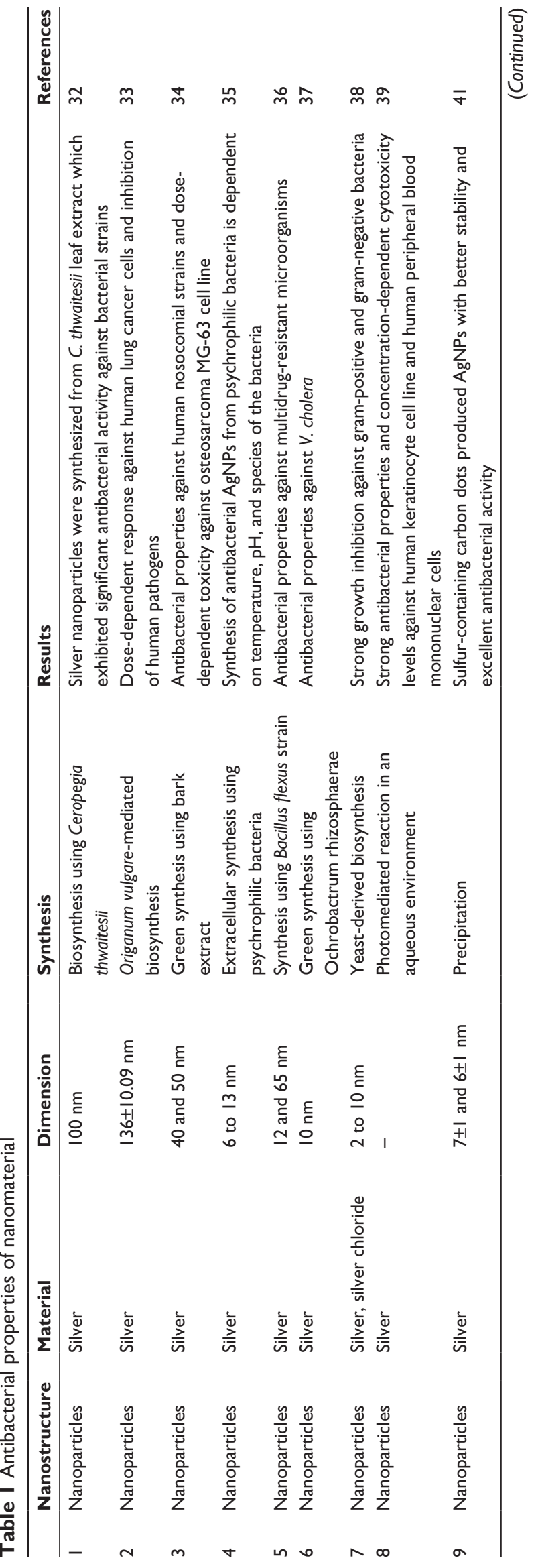




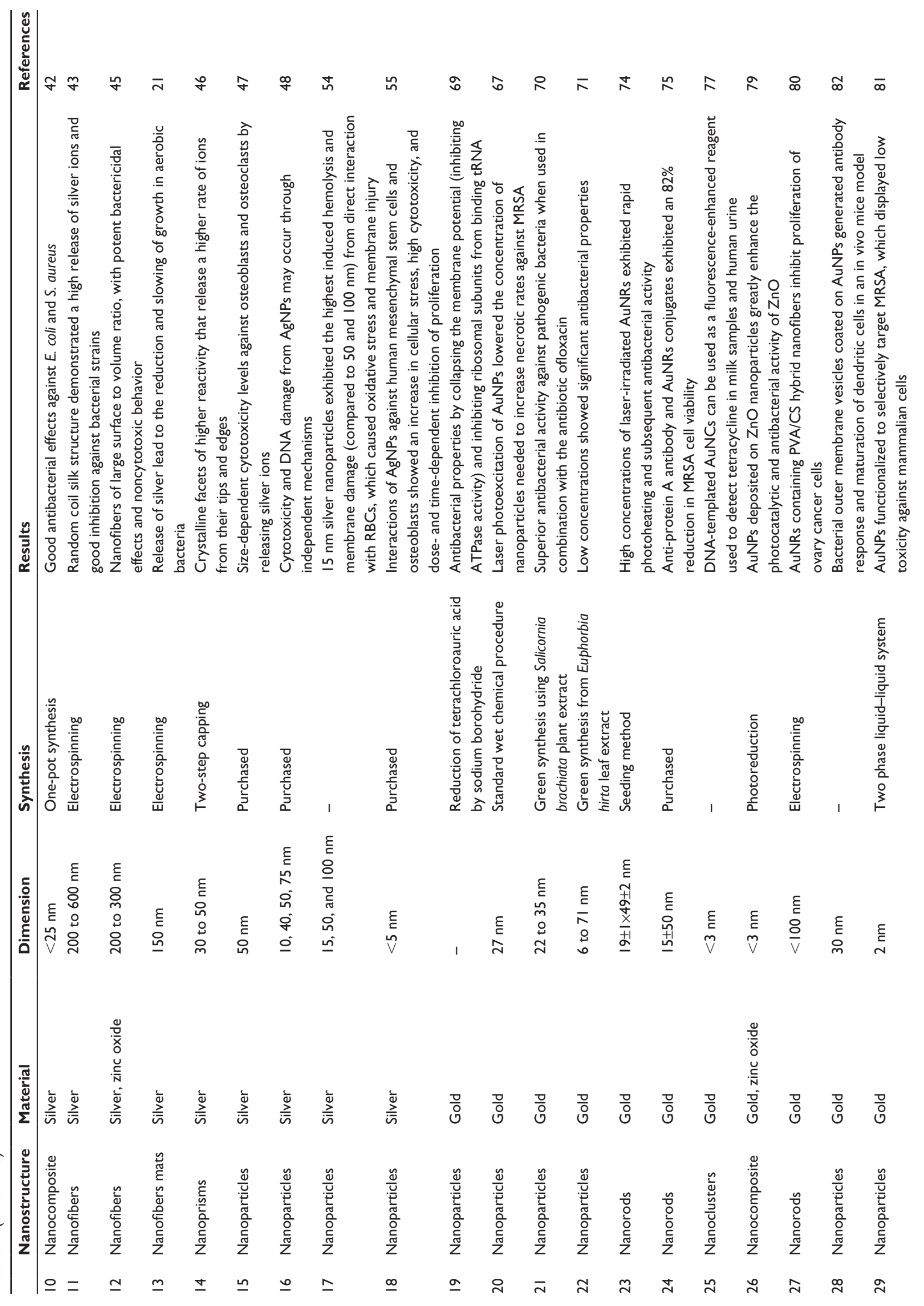



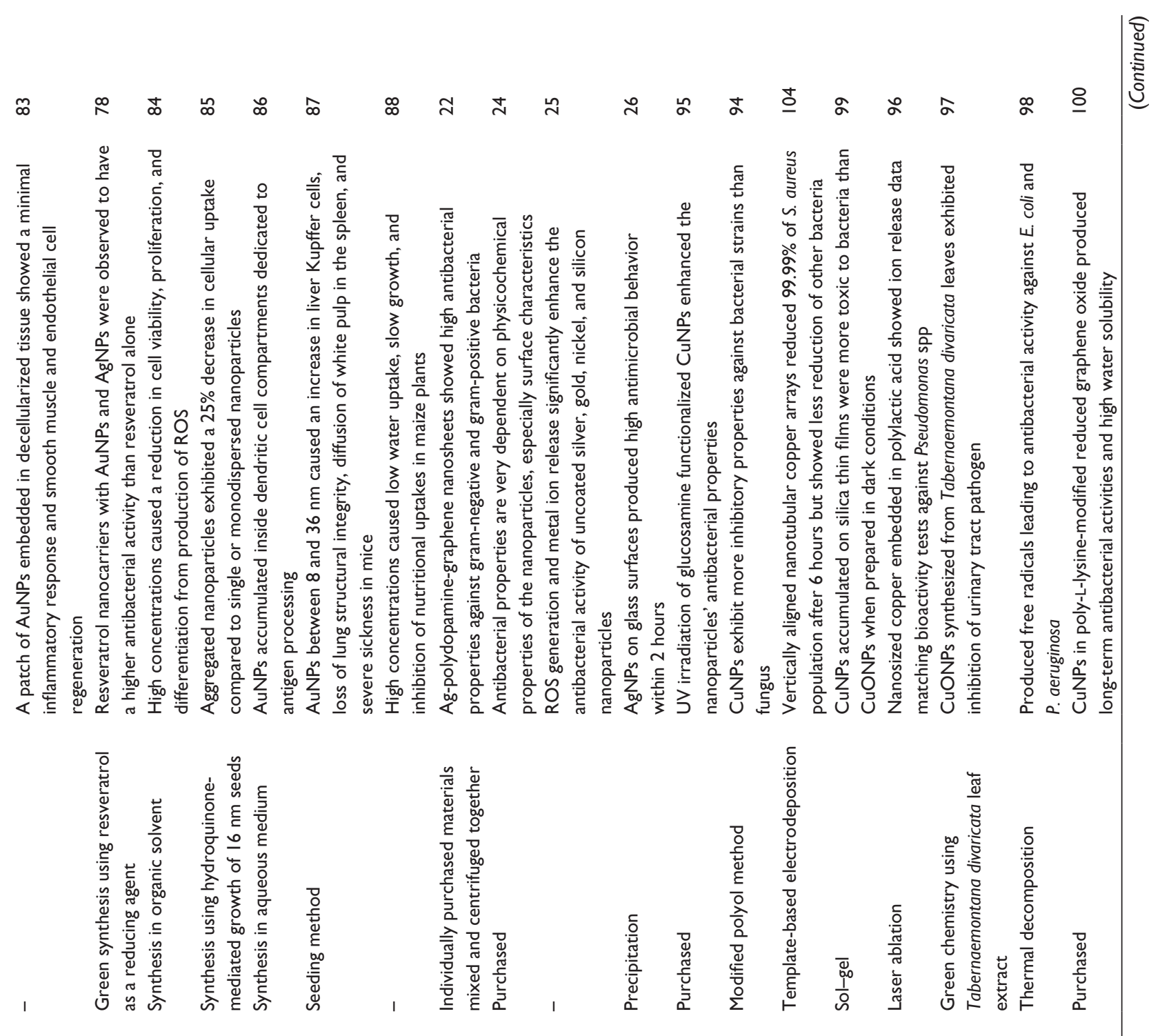

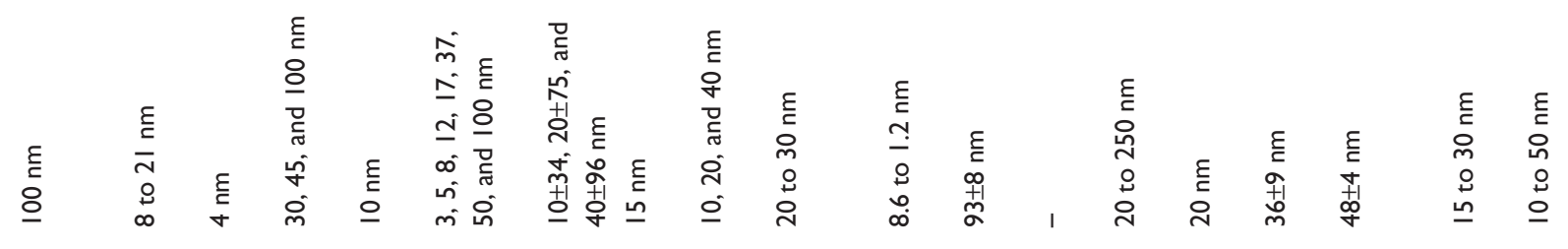

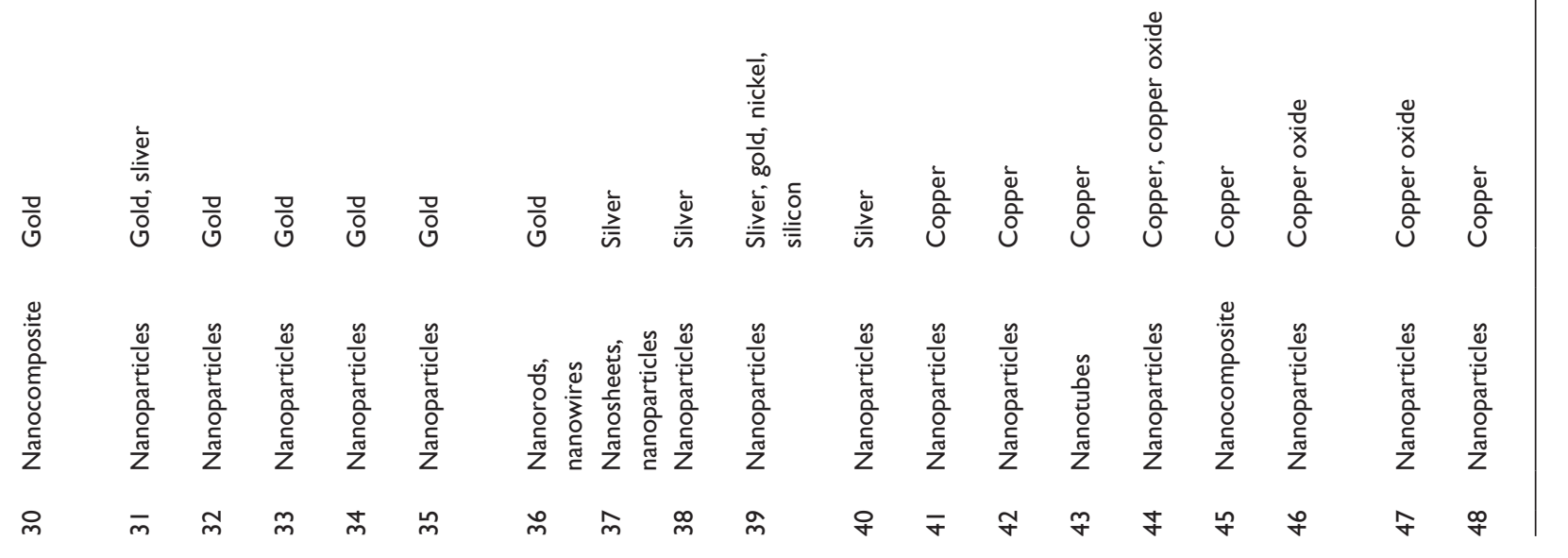




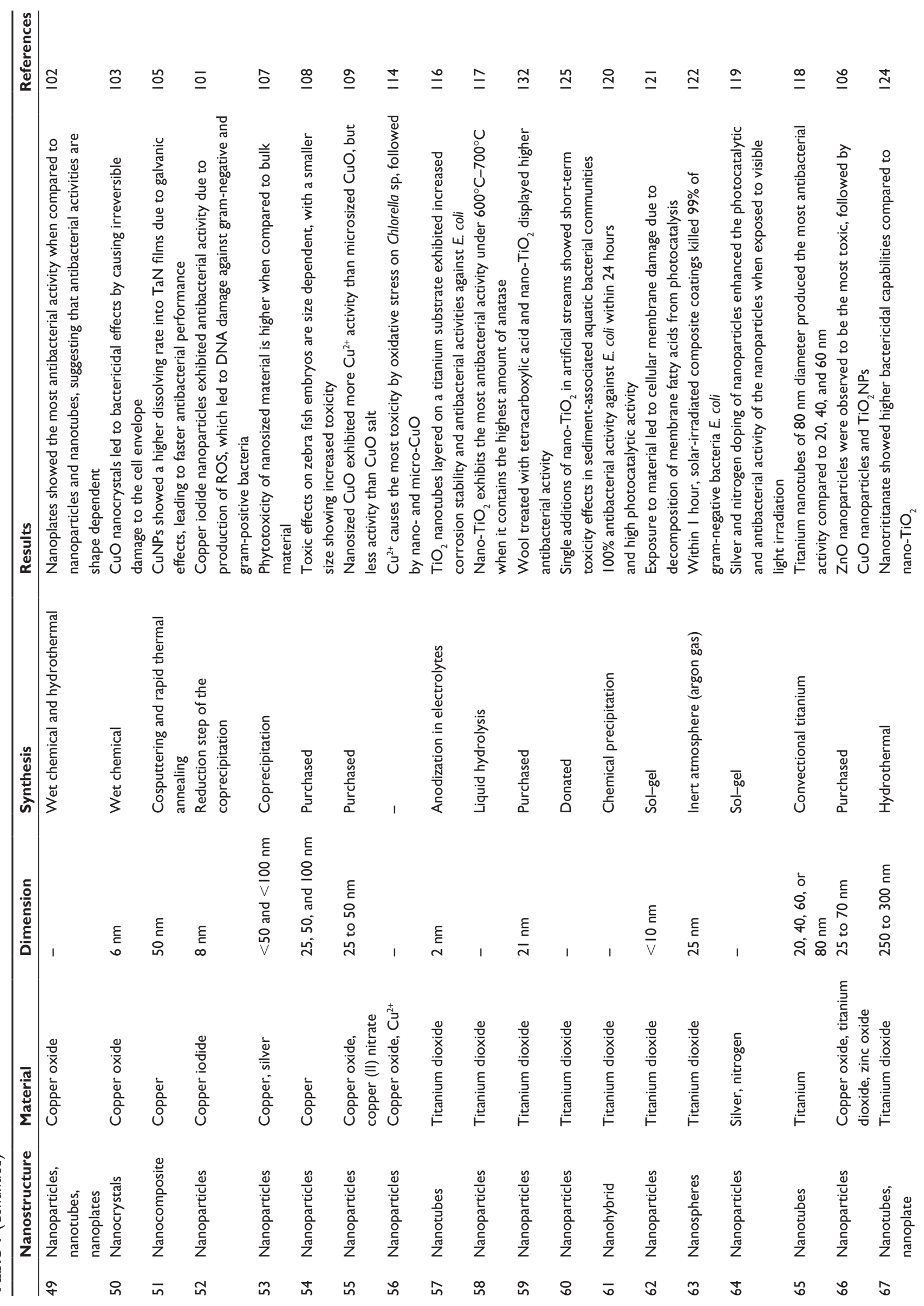



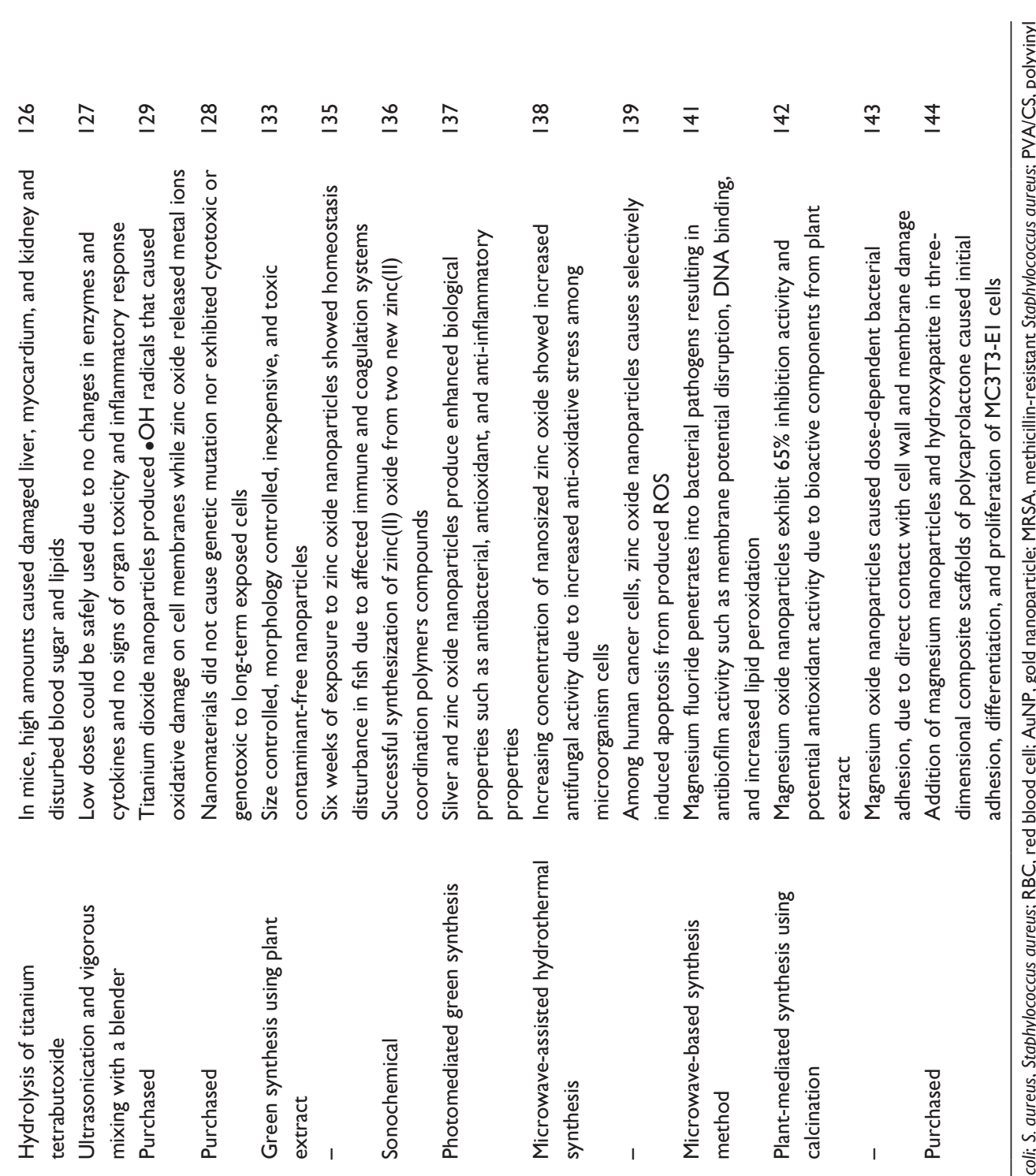

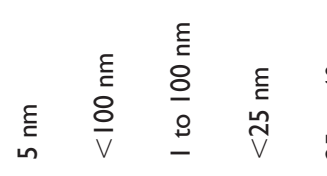

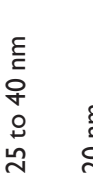
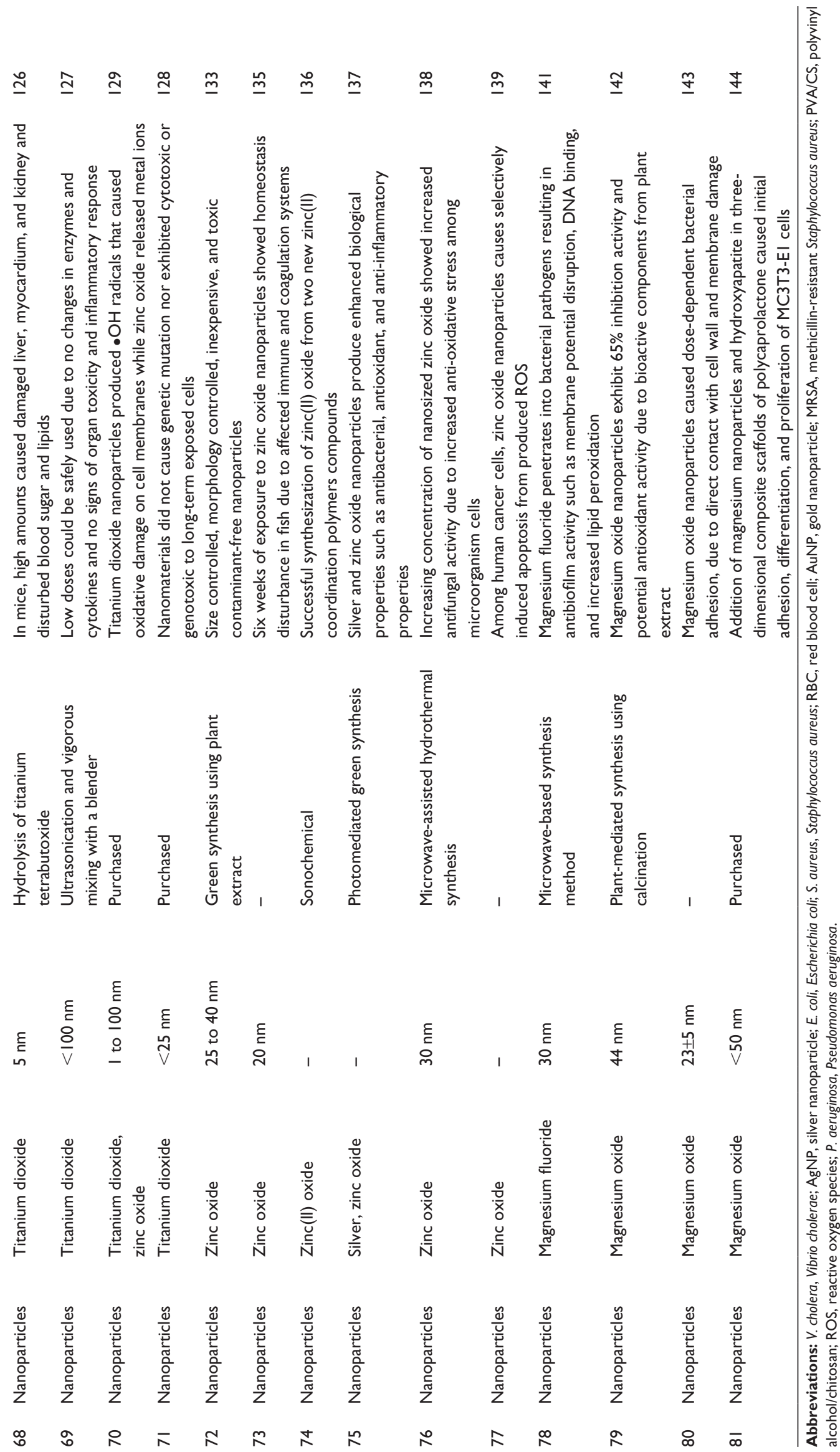
the dosage of nanomaterials inserted into living organisms to mitigate extreme toxicity effects on the body leading to biological damages. Many studies on the antibacterial effects of the aforementioned nanomaterials suggest that manipulating the physicochemical properties of the nanomaterials affects their resulting antibacterial activity. However, there is a large gap on the information on the exact mechanisms leading to these changes in antibacterial activity. Future studies should focus on investigating the effects of morphology and surface chemistry, especially for materials other than nanosilver.

\section{Acknowledgments}

This research was supported by the College of Engineering Faculty Startup Funds at California State University Long Beach and the National Institute of General Medical Sciences of the National Institutes of Health under Award Numbers: 8UL1GM118979, 8TL4GM118980, 8RL5GM118978, and U54GM119023. The content is solely the responsibility of the authors and does not necessarily represent the official views of the National Institutes of Health. Lei Yang would like to acknowledge National Natural Science Foundation of China (81622032, 51672184, and 51472279), the Priority Academic Program Development of Jiangsu High Education Institutions (PAPD), Jiangsu Innovation and Entrepreneurship Programs, and National Basic Research Program of China (973 Program, 2014CB748600) for supporting this work.

\section{Disclosure}

The authors report no conflicts of interest in this work.

\section{References}

1. Hecker JFC. Der schwarze tod im vierzehnten jahrhundert: Nach den quellen, für aerzte und gebildete nichtärzte [The black death and the dancing mania]. Berlin: Herbig; 1832. German.

2. Fauci AS, Morens DM. The perpetual challenge of infectious diseases. N Engl J Med. 2012;366(5):454-461.

3. Morens DM, Folkers GK, Fauci AS. Emerging infections: a perpetual challenge. Lancet Infect Dis. 2008;8(11):710-719.

4. Haensch S, Bianucci R, Signoli M, et al. Distinct clones of Yersinia pestis caused the black death. PLoS Pathog. 2010;6(10):e1001134.

5. Ali M, Nelson AR, Lopez AL, Sack DA. Updated global burden of cholera in endemic countries. PLoS Negl Trop Dis. 2015;9(6):e0003832.

6. Yeaman MR, Yount NY. Mechanisms of antimicrobial peptide action and resistance. Pharmacol Rev. 2003;55(1):27-55.

7. Tenover FC. Mechanisms of antimicrobial resistance in bacteria. Am J Med. 2006;119(6):S10.

8. Wright GD, Sutherland AD. New strategies for combating multidrugresistant bacteria. Trends Mol Med. 2007;13(6):260-267.

9. Kaltenpoth M, Göttler W, Herzner G, Strohm E. Symbiotic bacteria protect wasp larvae from fungal infestation. Curr Biol. 2005;15(5): 475-479.

10. Mitsuhashi S. Drug resistance in bacteria: history, genetics and biochemistry. J Int Med Res. 1993;21(1):1-14.

11. Chastre J. Evolving problems with resistant pathogens. Clin Microbiol Infect. 2008;14(s3):3-14.
12. Huh AJ, Kwon YJ. "Nanoantibiotics": a new paradigm for treating infectious diseases using nanomaterials in the antibiotics resistant era. J Control Release. 2011;156(2):128-145.

13. Kreuter J. Nanoparticles - a historical perspective. Int J Pharm. 2007; 331(1):1-10.

14. Zhou Y, Kong Y, Kundu S, Cirillo JD, Liang H. Antibacterial activities of gold and silver nanoparticles against Escherichia coli and bacillus Calmette-Guérin. J Nanobiotechnology. 2012;10(1):1.

15. Chernousova S, Epple M. Silver as antibacterial agent: ion, nanoparticle, and metal. Angew Chem Int Ed. 2013;52(6):1636-1653.

16. Barillo DJ, Marx DE. Silver in medicine: a brief history BC 335 to present. Burns. 2014;40(suppl 1):S8.

17. Chopra I. The increasing use of silver-based products as antimicrobial agents: a useful development or a cause for concern? Author's response. J Antimicrob Chemother. 2007;60(2):447-448.

18. Palomba M. Activity of antimicrobial silver polystyrene nanocomposites. J Nanomater. 2012;2012:1-7.

19. Fredj HB, Helali S, Esseghaier C, Vonna L, Vidal L, Abdelghani A. Labeled magnetic nanoparticles assembly on polypyrrole film for biosensor applications. Talanta. 2008;75(3):740-747.

20. Zhang Q, Yin Y. Beyond spheres: Murphy's silver nanorods and nanowires. Chem Commun. 2013;49(3):215-217.

21. Abdelgawad AM, Hudson SM, Rojas OJ. Antimicrobial wound dressing nanofiber mats from multicomponent (chitosan/silver-NPs/polyvinyl alcohol) systems. Carbohydr Polym. 2014;100:166-178.

22. Zhang Z, Zhang J, Zhang B, Tang J. Mussel-inspired functionalization of graphene for synthesizing Ag-polydopamine-graphene nanosheets as antibacterial materials. Nanoscale. 2013;5(1):118-123.

23. Millstone JE, Hurst SJ, Métraux GS, Cutler JI, Mirkin CA. Colloidal gold and silver triangular nanoprisms. Small. 2009;5(6):646-664.

24. Ivask A, ElBadawy A, Kaweeteerawat C, et al. Toxicity mechanisms in Escherichia coli vary for silver nanoparticles and differ from ionic silver. ACS Nano. 2013;8(1):374-386.

25. Zhang W, Li Y, Niu J, Chen Y. Photogeneration of reactive oxygen species on uncoated silver, gold, nickel, and silicon nanoparticles and their antibacterial effects. Langmuir. 2013;29(15):4647-4651.

26. Agnihotri S, Mukherji S, Mukherji S. Immobilized silver nanoparticles enhance contact killing and show highest efficacy: elucidation of the mechanism of bactericidal action of silver. Nanoscale. 2013;5(16): 7328-7340.

27. Sanchez C, Julián B, Belleville P, Popall M. Applications of hybrid organic-inorganic nanocomposites. J Mater Chem. 2005;15(35-36): 3559-3592.

28. Latif U, Al-Rubeaan K, Saeb AT. A review on antimicrobial chitosansilver nanocomposites: a roadmap toward pathogen targeted synthesis. Int J Polym. 2015;64(9):448-458.

29. Palza H. Antimicrobial polymers with metal nanoparticles. Int J Mol Sci. 2015;16(1):2099-2116.

30. Kapoor S, Lawless D, Kennepohl P, Meisel D, Serpone N. Reduction and aggregation of silver ions in aqueous gelatin solutions. Langmuir. 1994;10(9):3018-3022.

31. Hebbalalu D, Lalley J, Nadagouda MN, Varma RS. Greener techniques for the synthesis of silver nanoparticles using plant extracts, enzymes, bacteria, biodegradable polymers, and microwaves. ACS Sustain Chem Eng. 2013;1(7):703-712.

32. Muthukrishnan S, Bhakya S, Kumar TS, Rao MV. Biosynthesis, characterization and antibacterial effect of plant-mediated silver nanoparticles using Ceropegia thwaitesii - an endemic species. Ind Crops Prod. 2015; 63:119-124.

33. Sankar R, Karthik A, Prabu A, Karthik S, Shivashangari KS, Ravikumar V. Origanum vulgare mediated biosynthesis of silver nanoparticles for its antibacterial and anticancer activity. Colloids Surf B Biointerfaces. 2013;108:80-84.

34. Nayak D, Ashe S, Rauta PR, Kumari M, Nayak B. Bark extract mediated green synthesis of silver nanoparticles: evaluation of antimicrobial activity and antiproliferative response against osteosarcoma. Mater Sci Eng C. 2016;58:44-52. 
35. Shivaji S, Madhu S, Singh S. Extracellular synthesis of antibacterial silver nanoparticles using psychrophilic bacteria. Process Biochem. 2011;46(9):1800-1807.

36. Priyadarshini S, Gopinath V, Priyadharsshini NM, MubarakAli D, Velusamy P. Synthesis of anisotropic silver nanoparticles using novel strain, Bacillus flexus and its biomedical application. Colloids Surf B Biointerfaces. 2013;102:232-237.

37. Gahlawat G, Shikha S, Chaddha BS, Chaudhuri SR, Mayilraj S, Choudhury AR. Microbial glycolipoprotein-capped silver nanoparticles as emerging antibacterial agents against cholera. Microb Cell Fact. 2016;15(1):1.

38. Eugenio M, Müller N, Frasés S, et al. Yeast-derived biosynthesis of silver/silver chloride nanoparticles and their antiproliferative activity against bacteria. RSC Adv. 2016;6(12):9893-9904.

39. Banasiuk R, Frackowiak JE, Krychowiak M, et al. Synthesis of antimicrobial silver nanoparticles through a photomediated reaction in an aqueous environment. Int J Nanomedicine. 2016;11:315-324.

40. Zheng H, Wang Q, Long Y, Zhang H, Huang X, Zhu R. Enhancing the luminescence of carbon dots with a reduction pathway. Chem Commun 2011;47(38):10650-10652.

41. Jin J, Xu Z, Dong P, et al. One-step synthesis of silver nanoparticles using carbon dots as reducing and stabilizing agents and their antibacterial mechanisms. Carbon N Y. 2015;94:129-141.

42. Yadollahi M, Farhoudian S, Namazi H. One-pot synthesis of antibacterial chitosan/silver bio-nanocomposite hydrogel beads as drug delivery systems. Int J Biol Macromol. 2015;79:37-43.

43. Calamak S, Aksoy EA, Ertas N, Erdogdu C, Sagıroglu M, Ulubayram K $\mathrm{Ag} /$ silk fibroin nanofibers: effect of fibroin morphology on Ag release and antibacterial activity. Eur Polym J. 2015;67:99-112.

44. Black KC, Sileika TS, Yi J, Zhang R, Rivera JG, Messersmith PB Bacterial killing by light-triggered release of silver from biomimetic metal nanorods. Small. 2014;10(1):169-178.

45. Hassan MS. Bimetallic Zn/Ag doped polyurethane spider net composite nanofibers: a novel multipurpose electrospun mat. Ceram Int. 2013;39(3): 2503-2510.

46. Marta B, Jakab E, Potara M, et al. Pluronic-coated silver nanoprisms: synthesis, characterization and their antibacterial activity. Colloids Surf A Physicochem Eng Aspects. 2014;441:77-83.

47. Albers CE, Hofstetter W, Siebenrock KA, Landmann R, Klenke FM. In vitro cytotoxicity of silver nanoparticles on osteoblasts and osteoclasts at antibacterial concentrations. Nanotoxicology. 2013;7(1):30-36.

48. Gliga AR, Skoglund S, Wallinder IO, Fadeel B, Karlsson HL. Sizedependent cytotoxicity of silver nanoparticles in human lung cells: the role of cellular uptake, agglomeration and ag release. Part Fibre Toxicol. 2014;11(1):1.

49. Maiorano G, Sabella S, Sorce B, et al. Effects of cell culture media on the dynamic formation of protein-nanoparticle complexes and influence on the cellular response. ACS Nano. 2010;4(12):7481-7491.

50. Lee W, Kwak JI, An Y. Effect of silver nanoparticles in crop plants phaseolus radiatus and sorghum bicolor: media effect on phytotoxicity. Chemosphere. 2012;86(5):491-499.

51. Park CM, Chu KH, Heo J, et al. Environmental behavior of engineered nanomaterials in porous media: a review. J Hazard Mater. 2016;309: $133-150$.

52. Mudunkotuwa IA, Grassian VH. Biological and environmental media control oxide nanoparticle surface composition: the roles of biological components (proteins and amino acids), inorganic oxyanions and humic acid. Environ Sci Nano. 2015;2(5):429-439.

53. Zhao F, Zhao Y, Liu Y, Chang X, Chen C, Zhao Y. Cellular uptake, intracellular trafficking, and cytotoxicity of nanomaterials. Small. 2011; 7(10):1322-1337.

54. Chen LQ, Fang L, Ling J, Ding CZ, Kang B, Huang CZ. Nanotoxicity of silver nanoparticles to red blood cells: size dependent adsorption, uptake, and hemolytic activity. Chem Res Toxicol. 2015;28(3):501-509.

55. Pauksch L, Hartmann S, Rohnke M, et al. Biocompatibility of silver nanoparticles and silver ions in primary human mesenchymal stem cells and osteoblasts. Acta Biomater. 2014;10(1):439-449.
56. Wang Z, Chen J, Li X, Shao J, Peijnenburg WJ. Aquatic toxicity of nanosilver colloids to different trophic organisms: contributions of particles and free silver ion. Environ Toxicol Chem . 2012;31(10):2408-2413.

57. Wang Z, Quik JT, Song L, Van Den Brandhof E, Wouterse M, Peijnenburg WJ. Humic substances alleviate the aquatic toxicity of polyvinylpyrrolidone-coated silver nanoparticles to organisms of different trophic levels. Environ Toxicol Chem. 2015;34(6):1239-1245.

58. Gatoo MA, Naseem S, Arfat MY, Mahmood Dar A, Qasim K, Zubair S. Physicochemical properties of nanomaterials: implication in associated toxic manifestations. Biomed Res Int. 2014;2014:e498420.

59. Makama S, Piella J, Undas A, et al. Properties of silver nanoparticles influencing their uptake in and toxicity to the earthworm lumbricus rubellus following exposure in soil. Environ Pollut. 2016;218:870-878.

60. Zook JM, MacCuspie RI, Locascio LE, Halter MD, Elliott JT. Stable nanoparticle aggregates/agglomerates of different sizes and the effect of their size on hemolytic cytotoxicity. Nanotoxicology. 2011;5(4): 517-530.

61. Eustis S, El-Sayed MA. Why gold nanoparticles are more precious than pretty gold: noble metal surface plasmon resonance and its enhancement of the radiative and nonradiative properties of nanocrystals of different shapes. Chem Soc Rev. 2006;35(3):209-217.

62. Carnovale C, Bryant G, Shukla R, Bansal V. Size, shape and surface chemistry of nano-gold dictate its cellular interactions, uptake and toxicity. Prog Mater Sci. 2016;83:152-190.

63. Edwards PP, Thomas JM. Gold in a metallic divided state - from Faraday to present-day nanoscience. Angew Chem Int Ed. 2007;46(29): 5480-5486.

64. Desoize B. Metals and metal compounds in cancer treatment. Anticancer Res. 2004;24(3a):1529-1544.

65. Jain PK, Huang X, El-Sayed IH, El-Sayed MA. Noble metals on the nanoscale: optical and photothermal properties and some applications in imaging, sensing, biology, and medicine. Acc Chem Res. 2008;41(12): $1578-1586$.

66. Murphy C, Gole A, Stone J, et al. Gold nanoparticles in biology: beyond toxicity to cellular imaging. Acc Chem Res. 2008;41(12):1721-1730.

67. Mocan L, Ilie I, Tabaran FA, et al. Surface plasmon resonance-induced photoactivation of gold nanoparticles as mitochondria-targeted therapeutic agents for pancreatic cancer. Expert Opin Ther Targets. 2013; 17(12):1383-1393.

68. Liang R, Wei M, Evans DG, Duan X. Inorganic nanomaterials for bioimaging, targeted drug delivery and therapeutics. Chem Commun. 2014;50(91):14071-14081.

69. Cui Y, Zhao Y, Tian Y, Zhang W, Lü X, Jiang X. The molecular mechanism of action of bactericidal gold nanoparticles on Escherichia coli. Biomaterials. 2012;33(7):2327-2333.

70. Ahmed KBA, Subramanian S, Sivasubramanian A, Veerappan G, Veerappan A. Preparation of gold nanoparticles using salicornia brachiata plant extract and evaluation of catalytic and antibacterial activity. Spectrochim Acta A Mol Biomol Spectrosc. 2014;130:54-58.

71. Annamalai A, Christina V, Sudha D, Kalpana M, Lakshmi P. Green synthesis, characterization and antimicrobial activity of au NPs using Euphorbia hirta L. leaf extract. Colloids Surf B Biointerfaces. 2013; 108:60-65.

72. Khan AU, Yuan Q, Wei Y, et al. Photocatalytic and antibacterial response of biosynthesized gold nanoparticles. J Photochem Photobiol B. 2016;162:273-277.

73. Rizzello L, Sorce B, Sabella S, et al. Impact of nanoscale topography on genomics and proteomics of adherent bacteria. ACS Nano. 2011; 5(3):1865-1876.

74. Zhu Y, Ramasamy M, Yi DK. Antibacterial activity of ordered gold nanorod arrays. ACS Appl Mater Interfaces. 2014;6(17):15078-15085.

75. Shokri R, Salouti M, Zanjani RS. Anti protein A antibody-gold nanorods conjugate: a targeting agent for selective killing of methicillin resistant staphylococcus aureus using photothermal therapy method. JMicrobiol. 2015;53(2):116-121.

76. Zhang L, Wang E. Metal nanoclusters: new fluorescent probes for sensors and bioimaging. Nano Today. 2014;9(1):132-157. 
77. Yang X, Zhu S, Dou Y, Zhuo Y, Luo Y, Feng Y. Novel and remarkable enhanced-fluorescence system based on gold nanoclusters for detection of tetracycline. Talanta. 2014;122:36-42.

78. Park S, Cha S, Cho I, et al. Antibacterial nanocarriers of resveratrol with gold and silver nanoparticles. Mater Sci Eng C. 2016;58:1160-1169.

79. He W, Kim H, Wamer WG, Melka D, Callahan JH, Yin J. Photogenerated charge carriers and reactive oxygen species in $\mathrm{ZnO} / \mathrm{au}$ hybrid nanostructures with enhanced photocatalytic and antibacterial activity. J Am Chem Soc. 2013;136(2):750-757.

80. Yan E, Cao M, Wang Y, et al. Gold nanorods contained polyvinyl alcohol/chitosan nanofiber matrix for cell imaging and drug delivery. Mater Sci Eng C. 2016;58:1090-1097.

81. Li X, Robinson SM, Gupta A, et al. Functional gold nanoparticles as potent antimicrobial agents against multi-drug-resistant bacteria. ACS Nano. 2014;8(10):10682-10686.

82. Gao W, Fang RH, Thamphiwatana S, et al. Modulating antibacterial immunity via bacterial membrane-coated nanoparticles. Nano Lett. 2015; 15(2):1403-1409.

83. Ostdiek AM, Ivey JR, Grant DA, Gopaldas J, Grant SA. An in vivo study of a gold nanocomposite biomaterial for vascular repair. Biomaterials. 2015;65:175-183.

84. Soenen SJ, Manshian B, Montenegro JM, et al. Cytotoxic effects of gold nanoparticles: a multiparametric study. ACS Nano. 2012;6(7): 5767-5783.

85. Albanese A, Chan WC. Effect of gold nanoparticle aggregation on cell uptake and toxicity. ACS Nano. 2011;5(7):5478-5489.

86. Villiers CL, Freitas H, Couderc R, Villiers M, Marche PN. Analysis of the toxicity of gold nano particles on the immune system: effect on dendritic cell functions. $J$ Nanopart Res. 2010;12(1):55-60.

87. Chen Y, Hung Y, Liau I, Huang GS. Assessment of the in vivo toxicity of gold nanoparticles. Nanoscale Res Lett. 2009;4(8):858.

88. Moradi Shahmansouri N. Uptake, Translocation, and Toxicity of Gold Nanorods in Maize. Ann Arbor: The University of Iowa. 2014.

89. Ullah Khan A, Yuan Q, Wei Y, et al. Longan fruit juice mediated synthesis of uniformly dispersed spherical AuNPs: cytotoxicity against human breast cancer cell line MCF-7, antioxidant and fluorescent properties. RSC Adv. 2016;6(28):23775-23782.

90. Herbert EW. Red Gold of Africa: Copper in Precolonial History and Culture. London: University of Wisconsin Press; 1984.

91. Radetzki M. Seven thousand years in the service of humanity - the history of copper, the red metal. Resour Policy. 2009;34(4):176-184.

92. Scott-Fordsmand JJ, Weeks JM, Hopkin SP. Importance of contamination history for understanding toxicity of copper to earthworm Eisenia fetica (Oligochaeta: Annelida), using neutral-red retention assay. Environ Toxicol Chem. 2000;19(7):1774-1780.

93. Guisbiers G, Mejia-Rosales S, Khanal S, Ruiz-Zepeda F, Whetten RL, José-Yacaman M. Gold-copper nano-alloy, "tumbaga", in the era of nano: phase diagram and segregation. Nano Lett. 2014;14(11):6718-6726.

94. Ramyadevi J, Jeyasubramanian K, Marikani A, Rajakumar G, Rahuman AA. Synthesis and antimicrobial activity of copper nanoparticles. Mater Lett. 2012;71:114-116.

95. Veerapandian M, Sadhasivam S, Choi J, Yun K. Glucosamine functionalized copper nanoparticles: preparation, characterization and enhancement of anti-bacterial activity by ultraviolet irradiation. Chem Eng J. 2012;209:558-567.

96. Longano D, Ditaranto N, Cioffi N, et al. Analytical characterization of laser-generated copper nanoparticles for antibacterial composite food packaging. Anal Bioanal Chem. 2012;403(4):1179-1186.

97. Sivaraj R, Rahman PK, Rajiv P, Salam HA, Venckatesh R. Biogenic copper oxide nanoparticles synthesis using Tabernaemontana divaricata leaf extract and its antibacterial activity against urinary tract pathogen. Spectrochim Acta A Mol Biomol Spectrosc. 2014;133: $178-181$.

98. Das D, Nath BC, Phukon P, Dolui SK. Synthesis and evaluation of antioxidant and antibacterial behavior of $\mathrm{CuO}$ nanoparticles. Colloids Surf B Biointerfaces. 2013;101:430-433.
99. Akhavan $\mathrm{O}$, Ghaderi E. $\mathrm{Cu}$ and $\mathrm{CuO}$ nanoparticles immobilized by silica thin films as antibacterial materials and photocatalysts. Surf Coat Technol. 2010;205(1):219-223.

100. Ouyang Y, Cai X, Shi Q, et al. Poly-L-lysine-modified reduced graphene oxide stabilizes the copper nanoparticles with higher watersolubility and long-term additively antibacterial activity. Colloids Surf B Biointerfaces. 2013;107:107-114.

101. Pramanik A, Laha D, Bhattacharya D, Pramanik P, Karmakar P. A novel study of antibacterial activity of copper iodide nanoparticle mediated by DNA and membrane damage. Colloids Surf B Biointerfaces. 2012;96:50-55.

102. Ananth A, Dharaneedharan S, Heo M, Mok YS. Copper oxide nanomaterials: synthesis, characterization and structure-specific antibacterial performance. Chem Eng J. 2015;262:179-188.

103. Hassan MS, Amna T, Yang O, El-Newehy MH, Al-Deyab SS, Khil M. Smart copper oxide nanocrystals: synthesis, characterization, electrochemical and potent antibacterial activity. Colloids Surf B Biointerfaces. 2012;97:201-206.

104. Razeeb KM, Podporska-Carroll J, Jamal M, et al. Antimicrobial properties of vertically aligned nano-tubular copper. Mater Lett. 2014; 128:60-63.

105. Liu PC, Hsieh JH, Li C, Chang YK, Yang CC. Dissolution of cu nanoparticles and antibacterial behaviors of $\mathrm{TaN}-\mathrm{Cu}$ nanocomposite thin films. Thin Solid Films. 2009;517(17):4956-4960.

106. Aruoja V, Dubourguier H, Kasemets K, Kahru A. Toxicity of nanoparticles of $\mathrm{CuO}, \mathrm{ZnO}$ and $\mathrm{TiO} 2$ to microalgae Pseudokirchneriella subcapitata. Sci Total Environ. 2009;407(4):1461-1468.

107. Musante C, White JC. Toxicity of silver and copper to cucurbita pepo: differential effects of nano and bulk-size particles. Environ Toxicol. 2012;27(9):510-517.

108. Hua J, Vijver MG, Ahmad F, Richardson MK, Peijnenburg WJ. Toxicity of different-sized copper nano- and submicron particles and their shed copper ions to zebrafish embryos. Environ Toxicol Chem. 2014; 33(8):1774-1782.

109. McShane HV, Sunahara GI, Whalen JK, Hendershot WH. Differences in soil solution chemistry between soils amended with nanosized $\mathrm{CuO}$ or Cu reference materials: implications for nanotoxicity tests. Environ Sci Technol. 2014;48(14):8135-8142.

110. Gomes SI, Novais SC, Scott-Fordsmand JJ, De Coen W, Soares AM, Amorim MJ. Effect of Cu-nanoparticles versus cu-salt in Enchytraeus albidus (Oligochaeta): differential gene expression through microarray analysis. Comp Biochem Physiol C Toxicol Pharmacol. 2012;155(2):219-227.

111. Unrine J, Tsyusko O, Hunyadi S, Judy J, Bertsch P. Effects of particle size on chemical speciation and bioavailability of copper to earthworms (Eisenia fetida) exposed to copper nanoparticles. $J$ Environ Qual. 2010;39(6):1942-1953.

112. Dimkpa CO, Latta DE, McLean JE, Britt DW, Boyanov MI, Anderson AJ. Fate of $\mathrm{CuO}$ and $\mathrm{ZnO}$ nano-and microparticles in the plant environment. Environ Sci Technol. 2013;47(9):4734-4742.

113. Manusadžianas L, Caillet C, Fachetti L, et al. Toxicity of copper oxide nanoparticle suspensions to aquatic biota. Environ Toxicol Chem. 2012;31(1):108-114.

114. Wang L, Wang M, Peng C, Pan J. Toxic effects of nano-CuO, micro$\mathrm{CuO}$ and $\mathrm{cu}^{2+}$ on chlorella sp. J Environ Prot. 2013;4(1B):86.

115. Nakajima H, Okabe T. Titanium in dentistry: development and research in the U.S.A. Dent Mater J. 1996;15(2):77-90.

116. Dumitriu C, Popescu M, Ungureanu C, Pirvu C. Antibacterial efficiencies of TiO 2 nanostructured layers prepared in organic viscous electrolytes. Appl Surf Sci. 2015;341:157-165.

117. Yan X, Dai H, Li S. Preparation of nano-TiO2 by liquid hydrolysis and characterization of its antibacterial activity. $J$ Wuhan Univ Technol Mater Sci Ed. 2014;29(2):407-409.

118. Ercan B, Taylor E, Alpaslan E, Webster TJ. Diameter of titanium nanotubes influences anti-bacterial efficacy. Nanotechnology. 2011; 22(29):295102. 
119. Ashkarran AA, Hamidinezhad H, Haddadi H, Mahmoudi M. Doubledoped TiO 2 nanoparticles as an efficient visible-light-active photocatalyst and antibacterial agent under solar simulated light. Appl Surf Sci. 2014;301:338-345.

120. Haldorai Y, Shim J. Novel chitosan-TiO2 nanohybrid: preparation, characterization, antibacterial, and photocatalytic properties. Polym Compos. 2014;35(2):327-333.

121. Joost U, Juganson K, Visnapuu M, et al. Photocatalytic antibacterial activity of nano-TiO2 (anatase)-based thin films: effects on Escherichia coli cells and fatty acids. J Photochem Photobiol B. 2015;142:178-185.

122. Charpentier PA, Burgess K, Wang L, Chowdhury RR, Lotus AF, Moula G. Nano-TiO2/polyurethane composites for antibacterial and self-cleaning coatings. Nanotechnology. 2012;23(42):425606.

123. Jing Z, Guo D, Wang W, Zhang S, Qi W, Ling B. Comparative study of titania nanoparticles and nanotubes as antibacterial agents. Solid State Sci. 2011;13(9):1797-1803.

124. Pan R, Liu Y, Chen W, et al. The toxicity evaluation of nano-trititanate with bactericidal properties in vitro. Nanotoxicology. 2012;6(3): 327-337.

125. Ozaki A, Adams E, Binh CTT, et al. One-time addition of nano-TiO2 triggers short-term responses in benthic bacterial communities in artificial streams. Microb Ecol. 2016;71(2):266-275.

126. Liu H, Ma L, Zhao J, et al. Biochemical toxicity of nano-anatase TiO2 particles in mice. Biol Trace Elem Res. 2009;129(1-3):170-180.

127. Fabian E, Landsiedel R, Ma-Hock L, Wiench K, Wohlleben W, Van Ravenzwaay B. Tissue distribution and toxicity of intravenously administered titanium dioxide nanoparticles in rats. Arch Toxicol. 2008;82(3): $151-157$.

128. Wang S, Hunter LA, Arslan Z, Wilkerson MG, Wickliffe JK. Chronic exposure to nanosized, anatase titanium dioxide is not cyto- or genotoxic to Chinese hamster ovary cells. Environ Mol Mutagen. 2011; 52(8):614-622.

129. Xiong D, Fang T, Yu L, Sima X, Zhu W. Effects of nano-scale TiO2, $\mathrm{ZnO}$ and their bulk counterparts on zebrafish: acute toxicity, oxidative stress and oxidative damage. Sci Total Environ. 2011;409(8): 1444-1452.

130. Reck E, Richards M. Titanium dioxide - manufacture, environment and life cycle analysis: the tioxide experience. Surf Coat Int. 1997;80(12) 568-572.

131. Zhang H, Sun Y, Tian A, et al. Improved antibacterial activity and biocompatibility on vancomycin-loaded $\mathrm{TiO} 2$ nanotubes: in vivo and in vitro studies. Int J Nanomedicine. 2013;8:4379-4389.

132. Montazer M, Pakdel E, Behzadnia A. Novel feature of nano-titanium dioxide on textiles: antifelting and antibacterial wool. J Appl Polym Sci. 2011;121(6):3407-3413.
133. Mirzaei H, Darroudi M. Zinc oxide nanoparticles: biological synthesis and biomedical applications. Ceram Int. 2017;43(1):907-914.

134. Hu H, Zhang W, Qiao Y, Jiang X, Liu X, Ding C. Antibacterial activity and increased bone marrow stem cell functions of zn-incorporated TiO 2 coatings on titanium. Acta Biomater. 2012;8(2):904-915.

135. Chupani L, Zusková E, Niksirat H, et al. Effects of chronic dietary exposure of zinc oxide nanoparticles on the serum protein profile of juvenile common carp (Cyprinus carpio L.). Sci Total Environ. 2017; 579:1504-1511.

136. Fard MJS, Hayati P, Firoozadeh A, Janczak J. Ultrasonic synthesis of two new zinc (II) bipyridine coordination polymers: new precursors for preparation of zinc (II) oxide nano-particles. Ultrason Sonochem. 2017;35:502-513.

137. Thatoi P, Kerry RG, Gouda S, et al. Photo-mediated green synthesis of silver and zinc oxide nanoparticles using aqueous extracts of two mangrove plant species, Heritiera fomes and Sonneratia apetala and investigation of their biomedical applications. J Photochem Photobiol B. 2016;163:311-318.

138. Cierech M, Kolenda A, Grudniak AM, et al. Significance of polymethylmethacrylate (PMMA) modification by zinc oxide nanoparticles for fungal biofilm formation. Int J Pharm. 2016;510(1):323-335.

139. Akhtar MJ, Ahamed M, Kumar S, Khan MM, Ahmad J, Alrokayan SA Zinc oxide nanoparticles selectively induce apoptosis in human cancer cells through reactive oxygen species. Int J Nanomedicine. 2012; 7:845-857.

140. Kang M, Jang T, Kim SW, et al. MgF 2-coated porous magnesium/ alumina scaffolds with improved strength, corrosion resistance, and biological performance for biomedical applications. Mater Sci Eng C. 2016;62:634-642.

141. Lellouche J, Kahana E, Elias S, Gedanken A, Banin E. Antibiofilm activity of nanosized magnesium fluoride. Biomaterials. 2009;30(30): 5969-5978.

142. Sushma NJ, Prathyusha D, Swathi G, et al. Facile approach to synthesize magnesium oxide nanoparticles by using Clitoria ternatea characterization and in vitro antioxidant studies. Appl Nanosci. 2016; $6(3): 437-444$.

143. Wetteland CL, Nguyen NT, Liu H. Concentration-dependent behaviors of bone marrow derived mesenchymal stem cells and infectious bacteria toward magnesium oxide nanoparticles. Acta Biomater. 2016 35:341-356.

144. Roh H, Lee C, Hwang Y, et al. Addition of MgO nanoparticles and plasma surface treatment of three-dimensional printed polycaprolactone/hydroxyapatite scaffolds for improving bone regeneration. Mater Sci Eng C. 2017;74:525-535.
International Journal of Nanomedicine

\section{Publish your work in this journal}

The International Journal of Nanomedicine is an international, peerreviewed journal focusing on the application of nanotechnology in diagnostics, therapeutics, and drug delivery systems throughout the biomedical field. This journal is indexed on PubMed Central

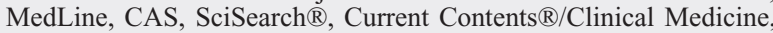

\section{Dovepress}

Journal Citation Reports/Science Edition, EMBase, Scopus and the Elsevier Bibliographic databases. The manuscript management system is completely online and includes a very quick and fair peer-review system, which is all easy to use. Visit http://www.dovepress.com/ testimonials.php to read real quotes from published authors. 